\title{
Research on the City Network Structure in the Yellow River Basin in China Based on Two-Way Time Distance Gravity Model and Social Network Analysis Method
}

\author{
Duo Chai (D), Dong Zhang, Yonghao Sun, and Shan Yang \\ School of Government, Central University of Finance and Economics, Beijing 100081, China \\ Correspondence should be addressed to Duo Chai; chaiduobnu@126.com
}

Received 8 October 2020; Revised 4 December 2020; Accepted 11 December 2020; Published 22 December 2020

Academic Editor: Fei Xiong

Copyright (c) 2020 Duo Chai et al. This is an open access article distributed under the Creative Commons Attribution License, which permits unrestricted use, distribution, and reproduction in any medium, provided the original work is properly cited.

\begin{abstract}
Modern cities form city networks through complex social ties. City network research is widely applied to guide regional planning, infrastructure construction, and resource allocation. China put forward the Yellow River Basin Development Strategy in 2019, but no research has been conducted on regional social connections among cities. Based on the gravity model modified by two-way "time distance" between cities, this is the first study to empirically examine the intensity and structure of the entire city network in the Yellow River basin using the social network analysis method and ArcGIS software. The connection rules of the cross-city transfer of city officials in the basin are also investigated to illustrate the official ties between cities. The results suggest that the intensity of two-way connections between cities is generally low in the Yellow River basin and there is a positive correlation between city network development level and regional economic development level. The development gap between cities on the north and south banks is larger than that between the east and west regions, and some cities in the middle and upper reaches of the river are marginalized in the network. The status of the central cities in the Yellow River basin is distinct, but their connecting and leading abilities are not strong, showing an inverted T-shaped spatial distribution. The subgroups of city networks have strong internal connections, while the connection among subgroups is weak and the development shows a partitioned and fragmented pattern, making it difficult to form linkages among the upper, middle, and lower reaches. The "beaded chain" spatial development strategy can be adopted in the river basin planning, giving priority to strengthening the links within subgroups of cities and among adjacent subgroups, building central city chains, and reinforcing the overall basin management.
\end{abstract}

\section{Introduction}

Modern metropolises and towns of different sizes have formed "macro-" social networks with various complex ties in politics, economy, and culture and have become a special field of social network research $[1,2]$. The main research contents of the analysis and graph mining of city networks include identifying the connection among cities, measuring the intensity of city network connections, and depicting the forms of city networks [3]. It is an effective method to reveal regional economic patterns, population distribution, and land development intensity and has been widely used in regional, spatial, and industrial planning, infrastructure construction layout, and other fields [4]. Over the past 40 years, cities in China have experienced rapid growth.
According to the China Statistical Yearbook, from 1978 to 2019, China's urbanization rate increased from $17.9 \%$ to $60.6 \%$, the number of cities increased from 193 to 672 , the urban population increased from 170 million to 840 million, and the urban construction land area increased from 6,720 square kilometers to 56,075.9 square kilometers. Driven by infrastructure construction such as highways, railways, and civil aviation systems, connection among cities has been continuously strengthened, forming many complex city networks [5]. The rapid formation of city networks in China provides an excellent subject for studies in city networks. In particular, research on city networks in river basins is a topic of significant current interest.

China's Yellow River basin includes nine provinces or autonomous regions, namely, Qinghai, Sichuan, Gansu, 
Ningxia, Inner Mongolia, Shaanxi, Shanxi, Henan, and Shandong. Historically, it is China's earliest developed area, and the river is known as the "Mother River." However, its resources and ecology are fragile. Since China's reform and opening-up, priority has been given to supporting the development of the southeast coastal regions, while cities in the Yellow River basin have been significantly neglected, becoming one of the areas in China with the most prominent problems such as unbalanced economic development, resource depletion, environmental pollution, and poverty [6]. To revitalize the Yellow River basin, China put forward a series of regional development plans, such as the "Great Western Development Strategy" in 2000 and the "Rise of Central China Plan" in 2004, strengthened investment in ecological protection and poverty alleviation, and built highspeed railways and highways on a large scale, which resulted in gradual economic growth and improved population movement among cities in the basin [7]. In September 2019, China introduced the "Ecological Protection and HighQuality Development of the Yellow River Basin" as a national strategy [8], in which building a high-quality city system in the basin and promoting balanced urban development are key objectives [9]. However, at present, there is hardly any research on the overall city network in the Yellow River basin to provide guidance for urban system development.

By using the two-way "time distance" modified gravity model, the social network analysis method, and ArcGIS software, this study took the cities in the Yellow River basin as a whole to study the spatial structure patterns and the intensity of the complex city network in the Yellow River basin. In addition, the official transfer network characteristics among cities were brought into the city network research for the first time, to illustrate political connections and cooperation possibilities among cities.

\section{Related Work}

Previously, research on city networks mainly studied the organizational structure of cities through road connections. Ardekani and Herman [10] studied the evolution of the connection structure between Austin and Dallas, two cities in Texas in the USA, using the technology of time-lapse aerial photography and the "two-fluid model," combined with ground experiments. Smith and Timberlake, Taylor et al., and Choi et al. [11-13] gradually introduced intercity connecting factors such as business, capital, and the Internet to improve the measurement methods for the structure, hierarchy, and density of city networks. Jarmon and Vanderleeuwm together with Neal $[14,15]$ designed the decision network analysis method, the interlocking world city network model, and the multisector network analysis method.

Among all types of city networks, the ones in river basins are unique. Because of connecting factors such as water conservancy, the environment, shipping, and population migration from the middle and upper reaches of rivers in inland areas to coastal areas, cities in river basins have a natural association with each other. Research on city networks can provide direct guidance for the overall river basin development planning [16]. Varol et al. together with Jennifer and Angel $[17,18]$ studied the Tigris and Euphrates River basins in Turkey and the Mississippi River basin urban agglomeration in the USA but still used the traditional geospatial distance analysis method. In the river basins' city networks studies in China, Wang and Zhuang in addition to Li et al. $[19,20]$ applied the methods of comprehensive scale analysis and diffusion potential analysis to study the urban agglomerations in the Yangtze River basin and the Pearl River basin. Wu et al. [21] applied an analytic hierarchy process and spatial autocorrelation to identify the functional nodes and network structure of the Haihe River basin urban agglomeration. Wang et al. [22] replaced the "linear distance" with the "shortest arrival time" between cities as the indicator of the strength of ties between cities to modify the gravity model. By using the modified gravity model and the aid of geographic information system technology (GIS), the spatial structure of the city network in the middle reaches of the Yangtze River was studied. The modified gravity model was enlightening for this study and will be further improved by considering the two-way arrival time difference between cities and comparing the shortest arrival time of highway and high-speed railways to determine the "time distance" between cities.

At present, there is hardly any research on the overall city network in the Yellow River basin, with only a few river basin sections studied. There is significantly more research on cities in the middle and lower reaches of the basin than on inland (relatively backward) cities in the upper reaches. Research on city networks in the lower reaches of the Yellow River has mainly focused on the Shandong Peninsula. Li [23] applied the information flow of "Baidu Index" to analyze the trend of decreased centrality and "flattened" development of the city network in this peninsula. C. Wang and M. Wang [24] analyzed the trend differences of increased or decreased concentrations of the connections between cities in different regions of Shandong Province. Cheng and Wang [25] investigated the mechanisms by which spatial distance and administrative level influence the city network structure in this province. Research on the city network in the middle reaches of the Yellow River has focused on the Central Plains urban agglomeration in Henan Province. Zhao et al. [26] constructed a Voronoi diagram of prefecturelevel cities in Henan Province and, based on the analysis of the number of coordinate cities to each central city and their spatial distance, identified the dense and "empty" areas of the city network. Miao and Wang, Meng and Lu, and Song and Liu [27-29] introduced transportation links and industrial links in their research on the city network of Zhengzhou urban agglomeration. In recent years, Geng and $\mathrm{Li}$ [30] have studied the city network structure of Shanxi Province and Shaanxi Province in the middle reaches of the Yellow River based on migration and communication data from Baidu.com. In the case of cities in provinces or autonomous regions in the upper reaches of the Yellow River, such as Gansu, Qinghai, Ningxia, and Inner Mongolia, very little research has been conducted on the connection structure between cities. 
Generally, there are three shortcomings in the existing research on city networks in the Yellow River basin. First, there is a lack of research on the overall river basin city network, especially those in the middle and upper reaches. Second, most studies carried out retrospective analyses on the intercity connection intensity based on indicators such as the distance between cities, the number of traffic lines, and the number of people who migrated in the past, but seldom used indicators such as the commuting time between cities that are closer to reality and reflect the current situation and potential closeness of communication between cities. In reality, although there was little connection among cities in the past such as through population movement, due to the large-scale construction of transportation facilities (e.g., high-speed railways) and logistics and information networks in China, commuting time between cities has been shortened significantly, and there may be much room for growth in future connection. As a result, former indicators could not comprehensively measure the potential for intercity connection, nor were they sufficient to guide future regional development planning and facility construction. The optimal evaluation index for the intensity and convenience of intercity transportation links has changed from "distance and number of passages" to "shortest arrival time." Third, existing studies have a common subjective error; that is, they assume that "City A to City B" and "City B to City A" have the same intensity of commuting connection, without distinguishing the forward and backward directions of intercity connection but calculating only a one-way connection. In reality, the lengths of intercity commuting time in the two directions are not necessarily the same, so it is necessary to consider all cities as individually equal and calculate the degree of the two-way connection.

\section{Materials and Methods}

3.1. Theoretical Analysis. The social connections between cities are very complex, and it is usually necessary to identify the main alternative indexes reflecting the intensity of connection [31]. By referring to the existing research, this paper makes the following inferences: the intensity of connection between two cities in terms of the economy and population movement mainly depends on two aspects: one is the size of the economy and population of the two cities. The larger the sizes of the two cities, the more the total volume and types of population and economic connection that could occur between them. The other is the commuting connection between the two cities $[5,22,32]$. The shorter the commuting time is, the stronger the connection is. Among them, commuting connection is a comprehensive indicator: first, commuting connection is the most important channel for intercity population movement and various political, economic, and cultural connections. Second, the construction of the existing commuting network between cities is based on the actual connection needs of population flow and logistics between the cities in the past and also reflects the overall arrangement and policy intention of the state for regional development. Third, intercity commuting connections can comprehensively reflect the present situation and future growth potential of the intercity population, logistics, and trade connections [33].

In the past, most studies selected the geographical distance or road distance between cities as the index to calculate commuting connection and held that the connection intensity between cities is inversely proportional to the square of commuting distance [27, 34]. However, because the twodimensional straight-line distance on a planar map does not take into account the factor of terrain, the fundamental changes in commuting efficiency between cities by the coverage of modern high-speed railways, and the difference in intercity commuting time in the two directions, distance between cities cannot accurately describe the actual intensity of the commuting connection between cities [35].

In view of these shortcomings, this paper takes the whole urban agglomeration of the Yellow River basin as the research object, consults the shortest arrival times of "City A to City B" and "City B to City A" one by one on Google Maps (highways) and the website of China Railway Customer Service Center, and constructs the shortest "time distance" matrix of two-way connections between cities. Then, the gravity model is constructed by introducing the indicators of urban population and economic aggregates, and the current and potential connection intensity of population, commerce, and logistics between cities in the Yellow River basin is calculated. Finally, the city network structure and status of cohesive subgroups in the Yellow River basin are measured by the social network analysis method, and the visual analysis of city network is carried out using ArcGIS software.

3.2. Research Objects and Data Sources. The Yellow River basin covers nine provinces or autonomous regions, namely, Qinghai, Sichuan, Gansu, Ningxia, Inner Mongolia, Shaanxi, Shanxi, Henan, and Shandong in China. After excluding nonurban areas, the research scope of this paper includes 78 prefecture-level cities in the nine provinces or autonomous regions. The research scope is shown in Figure 1 and the divisions of upper, middle, and lower reaches of Yellow River basin are shown in Figure 2.

The main data sources of this paper are shown in Table 1.

Table 2 shows that most of the key indicators of city development in the Yellow River basin are slightly higher than China's average level but significantly lower than those of cities in the Yangtze River basin. In particular, the table indicates that from 2015 to 2019 the average annual GDP growth rate in the Yellow River basin cities was lower than China's average level. In 2019, the average GDP of the 10 largest cities in the Yellow River basin was 557 billion yuan RMB and only Zhengzhou's GDP exceeded 1 trillion yuan $\mathrm{RMB}$. The average GDP of the 10 largest cities in the Yangtze River basin is 1704.8 billion yuan RMB, which is three times that of the Yellow River basin average value, and the GDP of eight cities exceeded 1 trillion yuan.

3.3. Test Method for Intercity Connection Intensity: Gravity Model Modified by Two-Way "Time Distance". The idea of a gravity model originated from the universal gravitation formula of Newtonian mechanics in physics and was 


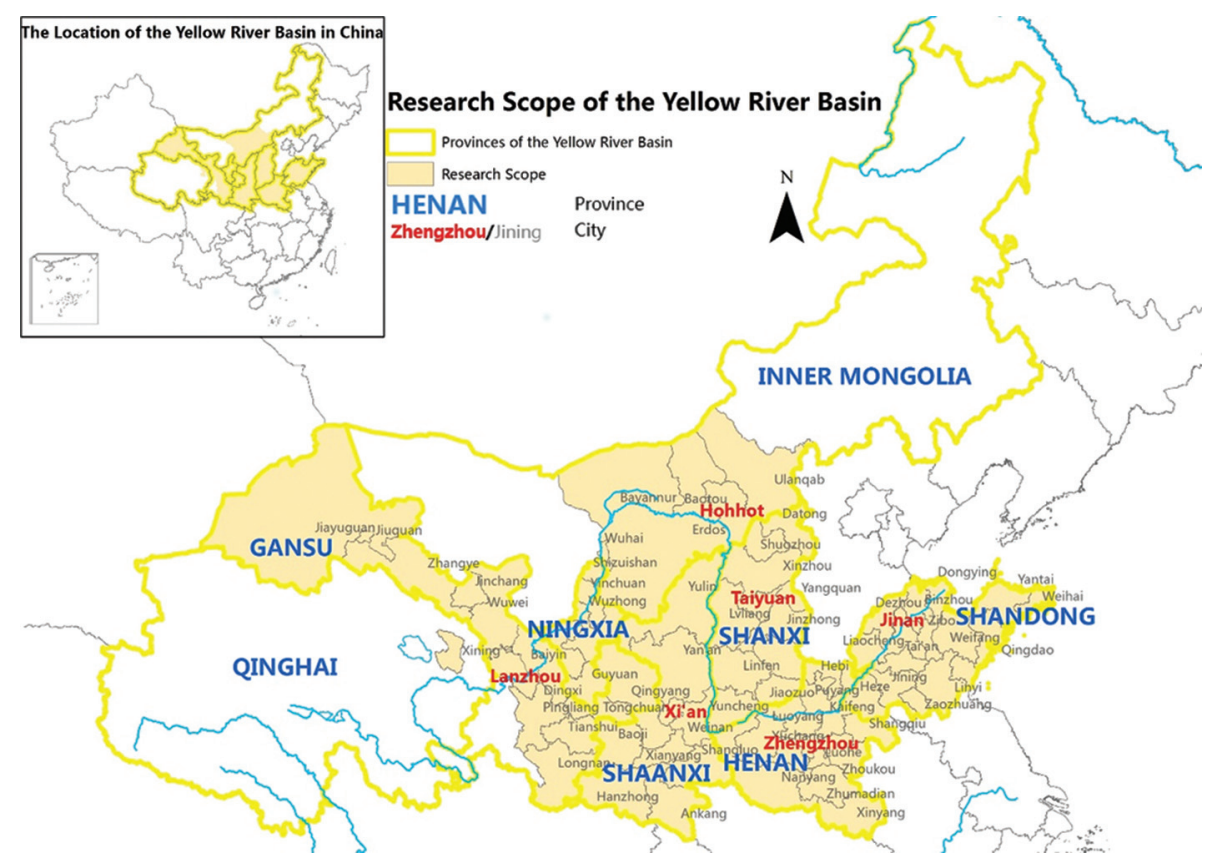

FIGURE 1: Schematic diagram of research scope.

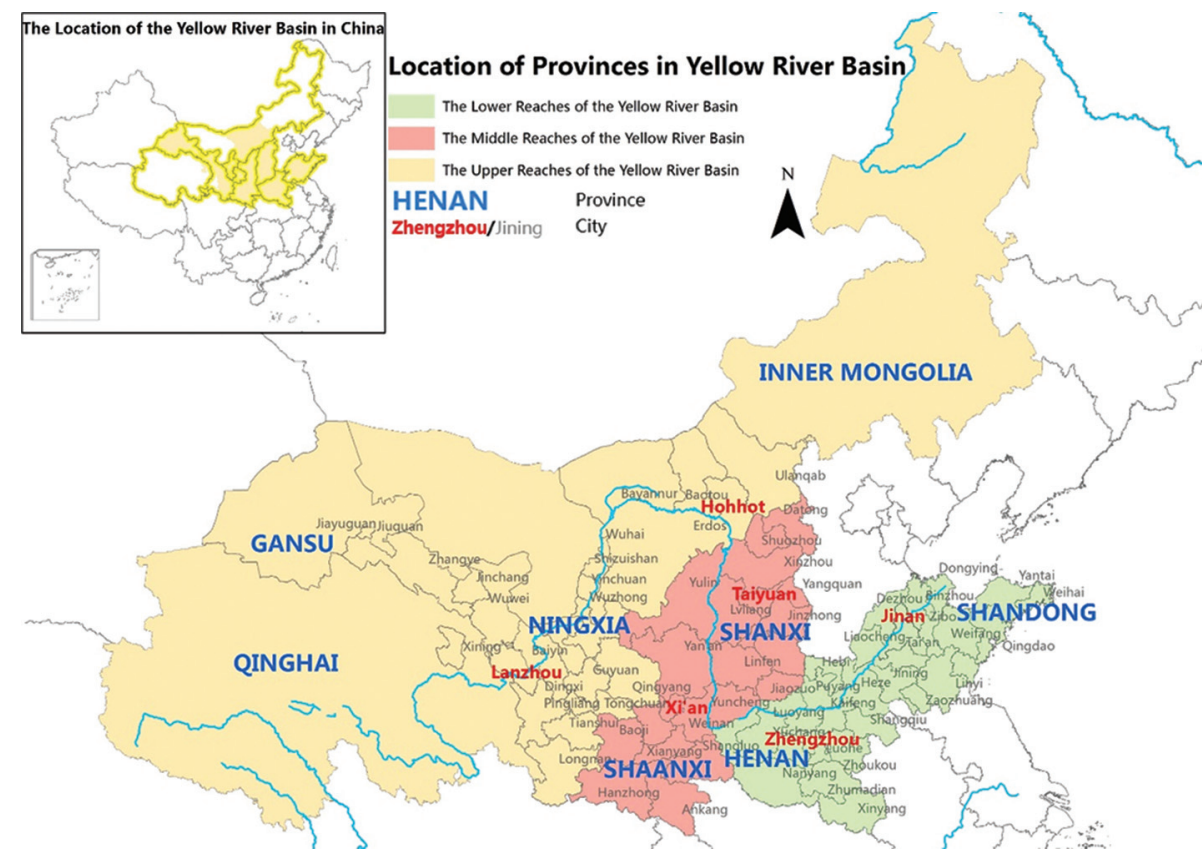

Figure 2: Location of provinces in Yellow River basin.

originally proposed by Tinbergen [36]. After improvement, it was introduced to calculate the intensity of two-way connections between cities $[37,38]$. It can reflect both the radiation ability of central cities to surrounding cities and the acceptance degree of the radiation ability of central cities by surrounding cities. In this paper, the gravity model is modified by the two-way "time distance" between cities. According to the assumption of the gravity model, the connection intensity between two cities is directly proportional to the total "weight" of the two cities and inversely proportional to the square of the shortest time distance between the two cities. The total "weight" of two cities can be expressed as the product of the GDP and the population of the two cities, while the time distance needs to be examined by comparing the shortest arrival time of various kinds of vehicles between cities.

Due to the limitation of hydrological conditions, the water transportation links between cities in the Yellow River basin are generally weak. In addition, they differ from the developed aviation in European and American countries. 
TABLE 1: Main sources of data studied in this paper.

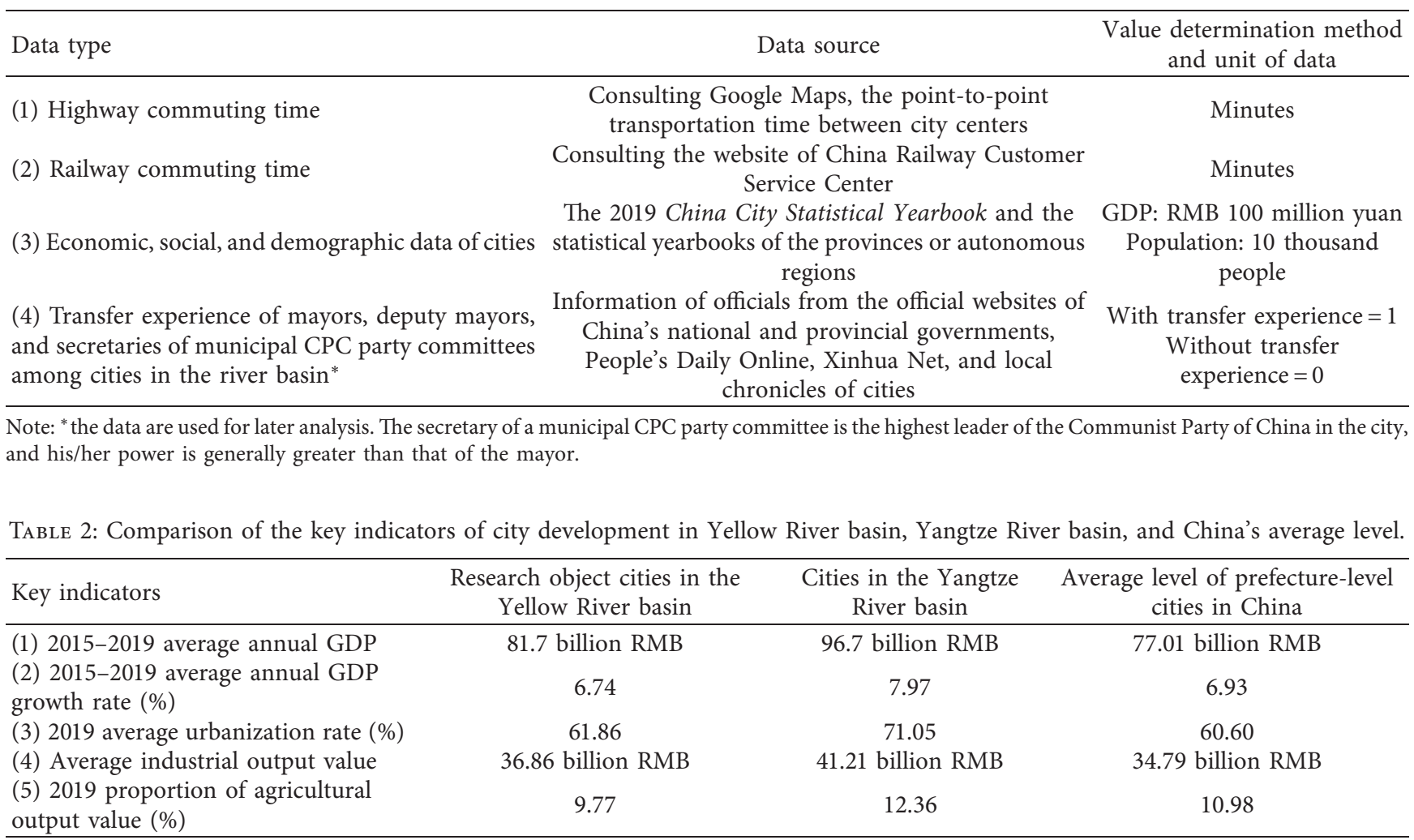

First, the development level of high-speed railways and highways in China's Yellow River basin is much higher than that of aviation facilities, and the speed of high-speed railways reaches $200-300 \mathrm{~km} / \mathrm{h}$. Because the income level of residents in the basin is relatively low and the cost of air travel is relatively high, high-speed railways and highways are residents' first choices for traveling. Residents will choose air travel only when necessary and time is tight. Second, according to the data on urban passenger transport and freight transport from China's Ministry of Transport in 2019, the total passenger and freight transport by civil aviation in the Yellow River basin only accounted for $0.57 \%$ compared with highways (36.42\%) and railways (59.91\%). Third, airports are generally far away from urban areas. If the time for commuting to and from airports, security checks, and waiting for the flight is calculated, the actual commuting time is similar to or more than that of taking the high-speed rail. Fourth, the number of flights, flight times, and attendance rates is greatly affected by weather and route adjustment. Therefore, flight data are not calculated here on the premise they are not relevant to the research objectives.

Based on the above reasons, the time distance in this paper is mainly obtained by examination and comparing the shortest arrival time of cars, ordinary trains, bullet trains, and high-speed trains between cities in the Yellow River basin that can be obtained by consulting road and railway traffic information websites.

At the same time, this paper has considered the difference of two-way arrival time between cities. The two-way time distance gravity model is shown in the following formula:

$$
\begin{aligned}
& R_{i j}=\frac{\sqrt{G_{i} P_{i}} \sqrt{G_{j} P_{j}}}{T_{i j}^{2}}, \\
& R_{i j}=\frac{\sqrt{G_{j} P_{j}} \sqrt{G_{i} P_{i}}}{T_{j i}^{2}} .
\end{aligned}
$$

In formula (1), $R_{i j}$ and $R_{j i}$ are the connection intensity of city $i$ to city $j$ and city $j$ to city $i$, respectively; $P_{i}$ and $P_{j}$ are the population sizes of city $i$ and city $j$, respectively; $G_{i}$ and $G_{j}$ are the GDP values of city $i$ and city $j$, respectively; $T_{i j}$ and $T_{j i}$ represent the shortest time distances from city $i$ to city $j$ and from city $j$ to city $i$, respectively. After identification, there are 6006 links between every two of the 78 prefecture-level cities in the Yellow River basin, which can be divided into 3003 pairs:

$$
\begin{aligned}
& F_{1}=\max \frac{\left(R_{i j}, R_{j i}\right)}{\sum_{i, j=1}^{n=78} R_{i j}}, \\
& F_{2}=\min \frac{\left(R_{i j}, R_{j i}\right)}{\sum_{j, i=1}^{n=78} R_{j i}} .
\end{aligned}
$$

In formula (2), $n$ is the number of cities, and $n=1,2,3$, $\ldots, 78 ; \max \left(R_{i j}, R_{j i}\right)$ and $\min \left(R_{i j}, R_{j i}\right)$ represent the larger 
and smaller values in the connection intensity of each pair of cities, respectively; $\sum_{i, j=1}^{n=78} R_{i j}$ represents the sum of the connection intensity values between every two cities; $F_{1}$ and $F_{2}$ can be used to compare the connection intensity among all cities and to analyze which cities have the strongest and weakest connections with each other in order to show the city network structure.

3.4. Analysis Method for City Network Structure: Social Network Analysis Method. Social network analysis (SNA) is applied to the study of network structure characteristics of social individuals (cities or people) and the importance of individuals in the network [39]. In recent years, SNA has been used to study connections among cities [40]. The main analysis indexes include three items: centrality, network density, and analysis of city cohesive subgroups.

3.4.1. Centrality. Centrality analysis mainly measures the leading force and attraction of cities in city networks [34], and the calculation indexes include degree centrality, closeness centrality, and betweenness centrality.

Degree centrality measures the number of connections between the city and other cities in the city network. It reflects the city's outward and inward connectivity (centrality), including "out-degree centrality" $C_{\text {od }}^{\prime}(i)$ and "indegree centrality" $C_{\mathrm{id}}^{\prime}(i)$. The calculation method is shown in the following formula. $X$ represents whether the city has a direct connection with other cities. If there is a direct connection, its value is 1 ; if there is no direct connection, its value is 0 . The larger $\sum_{j=1}^{n} X_{i j}$ and $\sum_{i=1}^{n} X_{j i}$, the more the connection of the city with other cities and the stronger its centrality:

$$
\begin{aligned}
& C_{\text {od }}^{\prime}(i)=\frac{\sum_{j=1}^{n} X_{i j}}{(n-1)}, \\
& C_{\text {id }}^{\prime}(i)=\frac{\sum_{i=1}^{n} X_{j i}}{(n-1)} .
\end{aligned}
$$

Closeness centrality measures the city's direct connection strength to other cities in the city network and is mainly based on the shortest time distance between cities in this paper. It reflects the level of the city's central function. The greater the closeness centrality, the stronger the direct connection between the city and other cities. Closeness centrality includes "out-closeness centrality" $C_{\mathrm{oc}}^{\prime}$ and "incloseness centrality" $C_{\mathrm{ic}}^{\prime}$, and the calculation method is as shown in the following formula. $d(i, j)$ represents the shortest time distance between a city $i$ and other cities $j$ :

$$
\begin{gathered}
C_{\mathrm{oc}}^{\prime}(i)=\frac{(n-1)}{\sum_{j=1}^{n} d(i, j)}, \\
C_{\mathrm{ic}}^{\prime}(i)=\frac{(n-1)}{\sum_{j=1}^{n} d(j . i)} .
\end{gathered}
$$

Betweenness centrality $C_{b}^{\prime}(i)$ measures the importance of a city acting as an intermediary for other cities in the city network, reflecting the intermediary function of the city. The calculation method is as shown in the following formula (5). $g_{j k}$ is the total number of shortest paths by which city $j$ connects city $k ; g_{j k}(i)$ refers to the number of shortest paths between city $j$ and city $k$ passing through city $i$

$$
C_{b}^{\prime}(i)=\frac{\sum_{j<k} g_{j k}\left(c_{j}\right) / g_{j k}}{(n-1)(n-2)}
$$

3.4.2. Network Density. Network density is an index reflecting the closeness and looseness of connection between cities in city networks.

The greater the network density, the closer the economic connection between cities. The calculation method is as shown in the following formula. $D$ is the network density; $m$ is the actual number of connections between cities in the city network, and $n$ is the number of cities. " $n \times(n-1)$ " is the theoretical maximum number of connections between cities. The formula shows that the network density is expressed by comparing the actual connection between cities and the theoretical maximum network connection:

$$
D=\frac{m}{[n \times(n-1)]} \text {. }
$$

3.4.3. Analysis of City Cohesive Subgroups. In some parts of a city network, groups of cities are particularly, directly, and closely connected and are known as "internal cohesive subgroups." By analyzing the number, composition, and interaction of cohesive subgroups in a city network, the distribution structure of urban agglomeration networks can be investigated as a whole $[41,42]$. In this paper, based on the data of city network connection intensity, UCINET6.5 software was applied to analyze the cohesive subgroups within the city networks in the Yellow River basin.

3.5. Supplementary Research: Analysis on Intercity Transfer of Officials. Under China's system, local officials have many social relations and resources and the right to make policies that can significantly impact regional development. At the provincial level, the fact that officials from developed provinces with outstanding achievements taking up posts in underdeveloped provinces is a common administrative means to strengthen interprovincial ties and cooperation and to support the development of underdeveloped regions. Officials holding office in different places develop important social relationships between cities.

The preliminary study in this paper showed that the number of officials transferred between cities in the Yellow River basin is small and concentrated locally, with excessively large regional differences, so this connection is not included in the overall study of city networks. However, in order to provide suggestions for strengthening connection between cities, this paper applied ArcGIS software for supplementary research on the transfer of mayoral-level officials among cities in the Yellow River basin and their office holding in different places. It also plotted a path 
diagram for the transfer of officials among cities to reflect the political connection and potential cooperation among cities.

\section{Results and Discussion}

4.1. Analysis of the Strength of Two-Way Economic Connection between Cities in the Yellow River Basin. The intensity of the two-way economic connection between cities in the Yellow River basin is calculated by modifying gravity model formulas (1) and (2), and a diagram of two-way connection intensity is plotted using ArcGIS 10.2 software, as shown in Figures 3 and 4 . Figure 3 represents the relatively high connection intensity $F_{1}$ in each pair of economic connection, while Figure 4 represents the relatively low connection intensity $F_{2}$ in each pair of economic connection. For clearer illustration, Figures 3 and 4 only show the connection with economic connection intensity values higher than RMB 100 million yuan $* 10,000$ people/minutes ${ }^{2}$.

Table 3 shows 60 pairs of cities with the strongest connection intensity among the 3003 pairs of cities in the Yellow River basin and the reverse connection intensity between them. The calculation results show the following:

(1) Generally, there is little difference in the intercity connection intensity in the two directions in the Yellow River basin, which indicates that most of the cities present a "reciprocal relationship" with similar mutual influence. A $F_{1} / F_{2}$ greater than 1 is mainly seen in the four capital cities, namely, Xi'an, Zhengzhou, Jinan, and Taiyuan, indicating that the connection of these four cities with other cities is significantly stronger than the connection of other cities with these four cities, which reflects the characteristics of central cities.

(2) The connection intensity values of cities in the Yellow River basin are quite different. The top five cities with the highest total connection intensity with other cities are Taiyuan (RMB 612.9 billion yuan $*$ people/minutes ${ }^{2}$ ), Zhengzhou (RMB 227 billion yuan $* 10,000$ people/minutes $\left.{ }^{2}\right)$, Xi' an (RMB 196.9 billion yuan $* 10,000$ people/minutes ${ }^{2}$ ), Jinan (RMB 165.6 billion yuan $* 10,000$ people/minutes ${ }^{2}$ ), and Xianyang (RMB 137.3 billion yuan $* 10,000$ people/minutes ${ }^{2}$ ). Longnan, Guyuan, Qingyang, Pingliang, and Baiyin are among other cities that have the lowest connection intensity values, which are all lower than RMB 1.5 billion yuan $* 10,000$ people/minutes ${ }^{2}$. This shows that the cities in the Yellow River basin generally present a "center-edge" city structure and the development is unbalanced among cities.

(3) There is a great regional difference in the connection intensity among cities in the Yellow River basin. In Figure 3, the intensity (relative thickness of lines) of city connection in the Yellow River basin shows significant trends of "south $>$ north" and "lower reach $>$ middle reach $>$ upper reach." The connection intensity and density among cities in Shandong Province in the lower reaches, as well as Shanxi
Province and Henan Province in the middle reaches, are higher than those in other regions. The connection among cities in the upper reaches of the river and cities on the north bank is significantly sparse, showing "voids," and the development of cities there is relatively isolated.

\subsection{An Analysis of City Network Structures in the Yellow River Basin}

4.2.1. An Analysis of the Centrality of Cities. Various types of centrality of cities in the Yellow River basin were calculated according to formulas (3)-(5). The results suggest the following:

(1) External connecting ability of cities: the distribution of out-degree centrality and out-closeness centrality of cities in the Yellow River basin is shown in Figures 5 and 6 . The average value of cities' out-degree centrality is only $20.8 \%$, showing that the external connectivity of cities in the Yellow River basin is generally low, while the average value of cities' outcloseness centrality is only $33.03 \%$, showing that the city's external connection ability is also relatively weak. The out-degree centrality values of Zhengzhou, Xi'an, and Jinan are only $18 \%, 9 \%$, and $9 \%$, respectively. Although the characteristics of the central cities are significant, their external connection and leading abilities are not strong. The weakness of central cities is a prominent problem in the backwardness of cities in the Yellow River basin.

(2) Attraction of cities: The average value of cities' indegree centrality is only $31.32 \%$, while the average value of cities' in-closeness centrality is only $37.61 \%$, which are relatively low levels. It can be seen from Figures 7 and 8 that the high-value areas of city indegree centrality and in-closeness centrality are still located in the central cities in the lower and middle reaches such as Jinan and Zhengzhou, while those values are significantly lower in the middle and upper reaches.

(3) Betweenness centrality: the average betweenness centrality of the city network basin is only $9.78 \%$, which indicates that the intermediary hub function of cities in the region is generally weak. It can be seen from Figure 9 that some cities in the middle and upper reaches of the Yellow River have a relatively high betweenness centrality instead. For example, the intermediary function of Xi'an and Lanzhou is higher than that of Zhengzhou and Taiyuan in the middle reaches as well as Jinan in the lower reaches. This shows that there are few connection nodes, simple contact ways, and single channels among cities in these regions. Most cities can only rely on a small number of cities to establish contact with other cities, and the city network structure remains in the traditional "single center-marginal cities" state. Guyuan, Ulanqab, Weihai, Jiayuguan, and other 


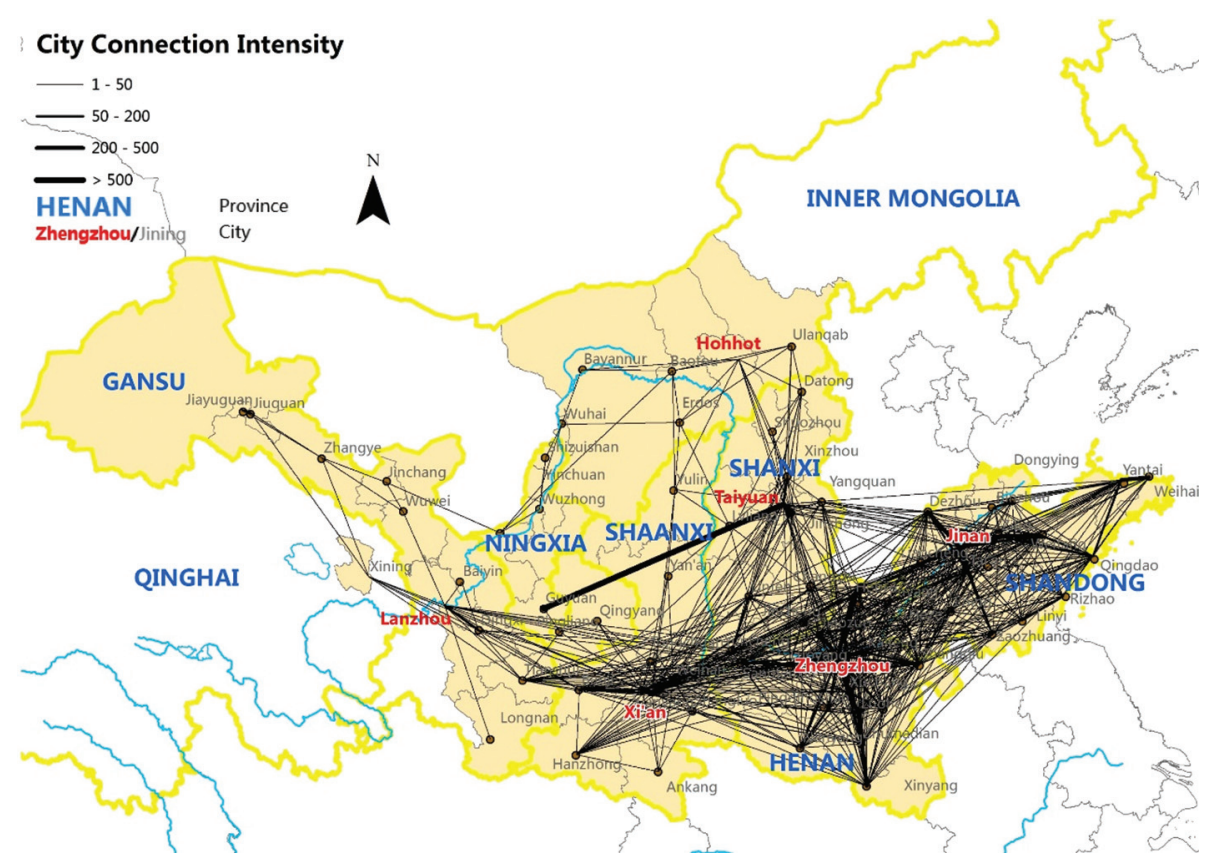

FIgURE 3: Distribution map of the maximum value of city connection intensity in the Yellow River basin.

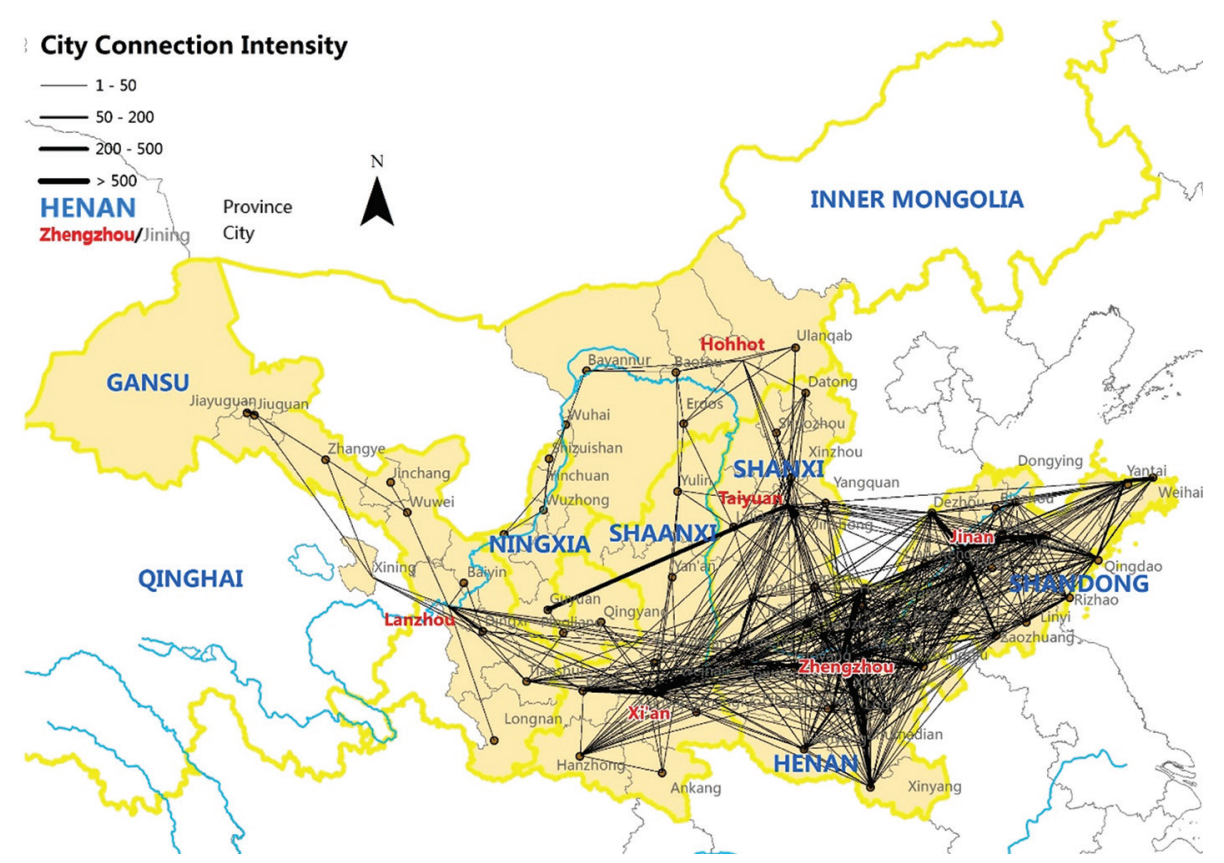

FIgURE 4: Distribution map of the minimum value of city connection intensity in the Yellow River basin.

cities have a betweenness centrality of 0 , indicating that they are marginalized in the city network.

4.2.2. Analysis on City Network Density. According to formula (6), the average density of city networks in the Yellow River basin is only $13.2 \%$. The levels of connection and integration in the development of urban agglomerations in the Yellow River basin are not high, and differentiation is significant. There are five areas with relatively high city networks density values, namely, the Shandong Peninsula urban agglomeration in the lower reaches of the Yellow River, the Zhengzhou and Taiyuan urban agglomerations in the middle reaches of the Yellow River, and the GansuShaanxi and Inner Mongolia-Ningxia urban areas in the upper reaches of the Yellow River. The total value of connection intensity among cities in these five regions accounts for $90 \%$ of that of the 3003 pairs of cities in the Yellow River basin. It can be seen from Table 4 that the city network density values of Shandong Peninsula, Zhengzhou, and 
TABLE 3: Top 60 (ranked by $F_{1}$ ) of intercity connection intensity in the Yellow River basin.

\begin{tabular}{|c|c|c|c|c|c|c|}
\hline Direction of connection & $F_{1}(\%)$ & $F_{1}$ ranking & Direction of connection & $F_{2}(\%)$ & $F_{2}$ ranking & $F_{1} / F_{2}$ \\
\hline Taiyuan-Guyuan & 7.462 & 1 & Guyuan-Taiyuan & 1.237 & 8 & 6.03 \\
\hline Xi'an-Xianyang & 3.559 & 2 & Xianyang-Xi'an & 3.559 & 1 & 1.00 \\
\hline Taiyuan-Jinzhong & 2.370 & 3 & Jinzhong-Taiyuan & 2.370 & 2 & 1.00 \\
\hline Jinan-Tai'an & 1.931 & 4 & Tai'an-Jinan & 1.931 & 3 & 1.00 \\
\hline Xi'an-Weinan & 1.733 & 5 & Weinan-Xi'an & 1.545 & 4 & 1.12 \\
\hline Zhengzhou-Xinxiang & 1.472 & 6 & Xinxiang-Zhengzhou & 1.472 & 5 & 1.00 \\
\hline Zhengzhou-Xuchang & 1.416 & 7 & Xuchang-Zhengzhou & 1.416 & 6 & 1.00 \\
\hline Zhengzhou-Kaifeng & 1.309 & 8 & Kaifeng-Zhengzhou & 1.309 & 7 & 1.00 \\
\hline Jinan-Zibo & 1.196 & 9 & Zibo-Jinan & 1.196 & 9 & 1.00 \\
\hline Hebi-Anyang & 0.987 & 10 & Anyang-Hebi & 0.987 & 10 & 1.00 \\
\hline Jinan-Dezhou & 0.957 & 11 & Dezhou-Jinan & 0.957 & 11 & 1.00 \\
\hline Xuchang-Luohe & 0.939 & 12 & Luohe-Xuchang & 0.939 & 12 & 1.00 \\
\hline Yantai-Weihai & 0.878 & 13 & Weihai-Yantai & 0.878 & 13 & 1.00 \\
\hline Zhumadian-Luohe & 0.796 & 14 & Luohe-Zhumadian & 0.796 & 14 & 1.00 \\
\hline Zibo-Weifang & 0.793 & 15 & Weifang-Zibo & 0.793 & 15 & 1.00 \\
\hline Xinxiang-Hebi & 0.788 & 16 & Hebi-Xinxiang & 0.788 & 16 & 1.00 \\
\hline Zhengzhou-Jiaozuo & 0.611 & 17 & Jiaozuo-Zhengzhou & 0.445 & 23 & 1.37 \\
\hline Zhumadian-Xinyang & 0.608 & 18 & Xinyang-Zhumadian & 0.608 & 17 & 1.00 \\
\hline Nanyang-Pingdingshan & 0.576 & 19 & Pingdingshan-Nanyang & 0.536 & 19 & 1.08 \\
\hline Zhengzhou-Luoyang & 0.552 & 20 & Luoyang-Zhengzhou & 0.552 & 18 & 1.00 \\
\hline Zhoukou-Xuchang & 0.539 & 21 & Xuchang-Zhoukou & 0.501 & 21 & 1.08 \\
\hline Xinxiang-Anyang & 0.514 & 22 & Anyang-Xinxiang & 0.514 & 20 & 1.00 \\
\hline Rizhao-Linyi & 0.447 & 23 & Linyi-Rizhao & 0.447 & 22 & 1.00 \\
\hline Xuchang-Zhumadian & 0.429 & 24 & Zhumadian-Xuchang & 0.352 & 27 & 1.22 \\
\hline Qingdao-Weifang & 0.420 & 25 & Weifang-Qingdao & 0.420 & 24 & 1.00 \\
\hline Jinan-Weifang & 0.373 & 26 & Weifang-Jinan & 0.373 & 25 & 1.00 \\
\hline Zhengzhou-Luohe & 0.372 & 27 & Luohe-Zhengzhou & 0.372 & 26 & 1.00 \\
\hline Luoyang-Sanmenxia & 0.342 & 28 & Sanmenxia-Luoyang & 0.320 & 30 & 1.07 \\
\hline Zhengzhou-Hebi & 0.341 & 29 & Hebi-Zhengzhou & 0.341 & 28 & 1.00 \\
\hline Zhengzhou-Anyang & 0.336 & 30 & Anyang-Zhengzhou & 0.336 & 29 & 1.00 \\
\hline Tai'an-Dezhou & 0.328 & 31 & Dezhou-Tai'an & 0.230 & 38 & 1.43 \\
\hline Jiuquan-Jiayuguan & 0.312 & 32 & Jiayuguan-Jiuquan & 0.312 & 31 & 1.00 \\
\hline Shangqiu-Kaifeng & 0.292 & 33 & Kaifeng-Shangqiu & 0.292 & 32 & 1.00 \\
\hline Zhengzhou-Zhumadian & 0.287 & 34 & Zhumadian-Zhengzhou & 0.287 & 33 & 1.00 \\
\hline Zhengzhou-Pingdingshan & 0.281 & 35 & Pingdingshan-Zhengzhou & 0.269 & 34 & 1.05 \\
\hline Zhoukou-Zhengzhou & 0.265 & 36 & Zhengzhou-Zhoukou & 0.265 & 35 & 1.00 \\
\hline Zhengzhou-Shangqiu & 0.256 & 37 & Shangqiu-Zhengzhou & 0.256 & 36 & 1.00 \\
\hline Zaozhuang-Tai'an & 0.245 & 38 & Tai'an-Zaozhuang & 0.245 & 37 & 1.00 \\
\hline Xi'an-Baoji & 0.241 & 39 & Baoji-Xi'an & 0.203 & 41 & 1.19 \\
\hline Xianyang-Weinan & 0.218 & 40 & Weinan-Xianyang & 0.218 & 39 & 1.00 \\
\hline Taiyuan-Xinzhou & 0.210 & 41 & Xinzhou-Taiyuan & 0.210 & 40 & 1.00 \\
\hline Lanzhou-Dingxi & 0.202 & 42 & Dingxi-Lanzhou & 0.202 & 42 & 1.00 \\
\hline Baoji-Xianyang & 0.202 & 43 & Xianyang-Baoji & 0.182 & 46 & 1.11 \\
\hline Linfen-Yuncheng & 0.197 & 44 & Yuncheng-Linfen & 0.197 & 43 & 1.00 \\
\hline Binzhou-Dongying & 0.194 & 45 & Dongying-Binzhou & 0.167 & 48 & 1.16 \\
\hline Qingdao-Yantai & 0.188 & 46 & Yantai-Qingdao & 0.188 & 44 & 1.00 \\
\hline Jinan-Zaozhuang & 0.184 & 47 & Zaozhuang-Jinan & 0.184 & 45 & 1.00 \\
\hline Xinyang-Luohe & 0.175 & 48 & Luohe-Xinyang & 0.175 & 47 & 1.00 \\
\hline Xinxiang-Xuchang & 0.165 & 49 & Xuchang-Xinxiang & 0.158 & 49 & 1.04 \\
\hline Zhengzhou-Nanyang & 0.164 & 50 & Nanyang-Zhengzhou & 0.146 & 53 & 1.12 \\
\hline Shangqiu-Heze & 0.157 & 51 & Heze-Shangqiu & 0.136 & 55 & 1.16 \\
\hline Qingdao-Zibo & 0.152 & 52 & Zibo-Qingdao & 0.152 & 50 & 1.00 \\
\hline Xi'an-Sanmenxia & 0.150 & 53 & Sanmenxia-Xi'an & 0.150 & 51 & 1.00 \\
\hline Weinan-Sanmenxia & 0.149 & 54 & Sanmenxia-Weinan & 0.142 & 54 & 1.05 \\
\hline Xuchang-Xinyang & 0.147 & 55 & Xinyang-Xuchang & 0.147 & 52 & 1.00 \\
\hline Kaifeng-Xuchang & 0.147 & 56 & Xuchang-Kaifeng & 0.026 & 163 & 5.72 \\
\hline Hohhot-Ulanqab & 0.135 & 57 & Ulanqab-Hohhot & 0.135 & 56 & 1.00 \\
\hline Zhengzhou-Xinyang & 0.133 & 58 & Xinyang-Zhengzhou & 0.129 & 58 & 1.03 \\
\hline Weinan-Yuncheng & 0.133 & 59 & Yuncheng-Weinan & 0.133 & 57 & 1.00 \\
\hline Dezhou-Zibo & 0.127 & 60 & Zibo-Dezhou & 0.127 & 59 & 1.00 \\
\hline
\end{tabular}




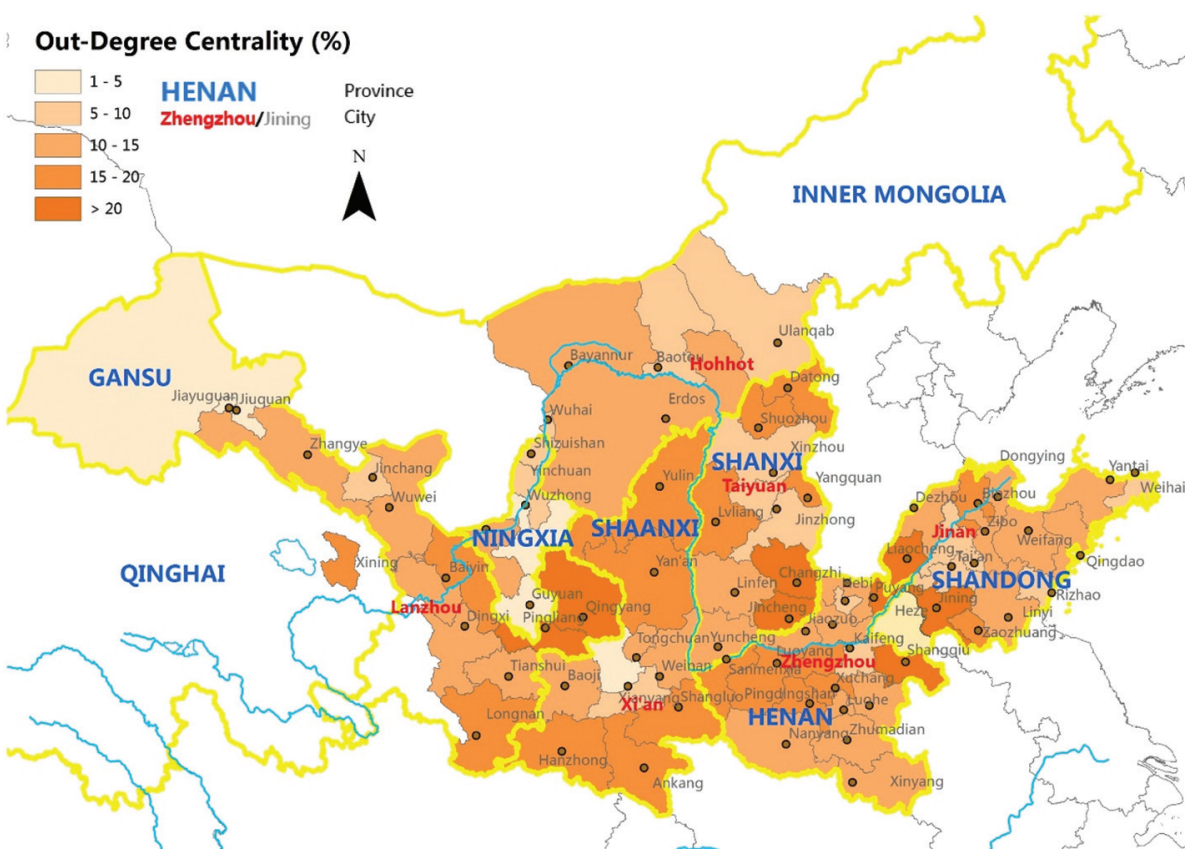

FIgURE 5: Distribution map of out-degree centrality of cities in the Yellow River basin.

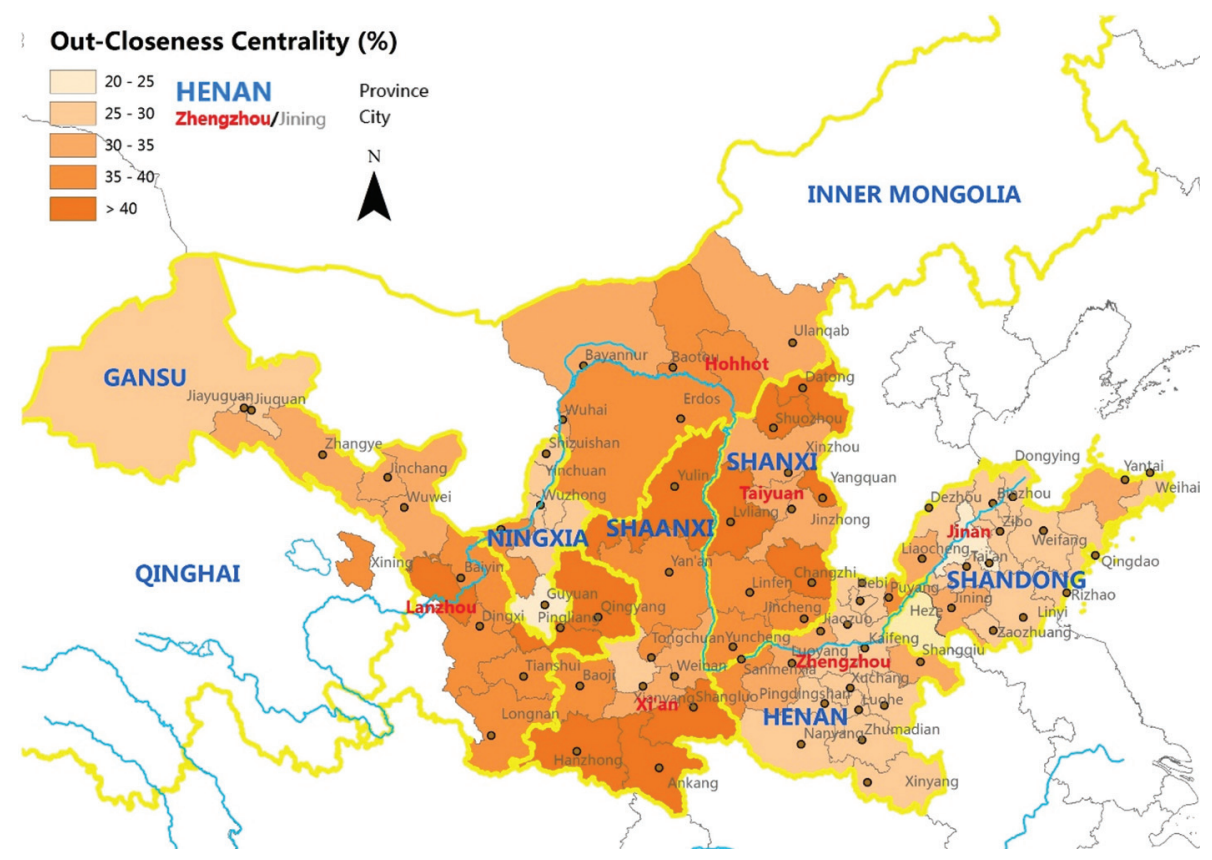

FIGURE 6: Distribution map of out-closeness centrality of cities in the Yellow River basin.

Taiyuan urban agglomerations are all over $50 \%$, while that of Gansu-Shaanxi urban agglomerations is only $26.5 \%$.

It can be seen from Figure 10 that the network density of urban agglomerations in the Yellow River basin is also dense in the east and sparse in the west and dense in the south and sparse in the north and that the development gap between cities on the north and south banks is larger than that between the east and west regions. Although the central cities are not strong, the overall "central-edge" city structure in the basin is clear. Zhengzhou City, Henan Province, has the highest network density in the middle reaches of the Yellow River, followed by Xi' an City, Lanzhou City, and Jinan City, which are arranged on an east-west axis. Taiyuan City, Linfen City, and Changzhi City of Shanxi Province in the middle reaches of the Yellow River are the main channels connecting the south and north banks, but their ability of 


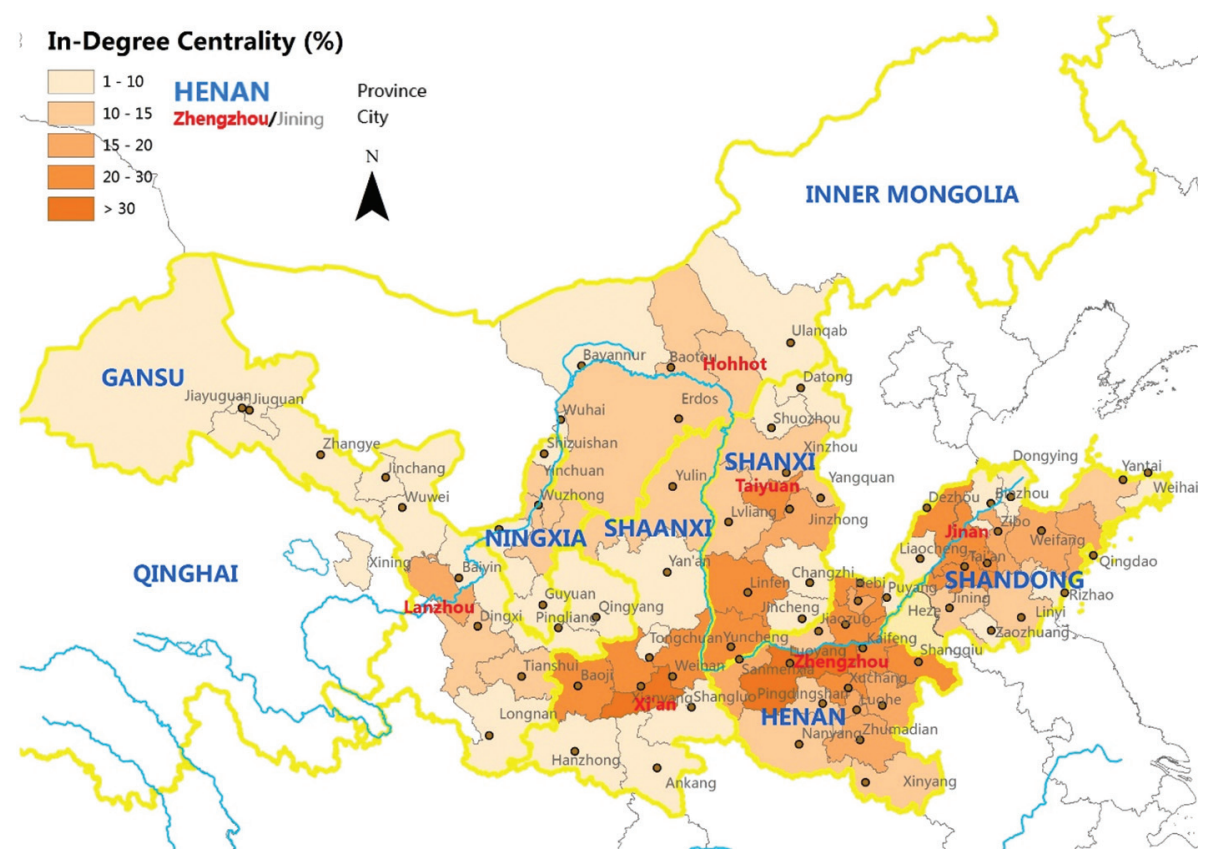

FIgURE 7: Distribution map of in-degree centrality of cities in the Yellow River basin.

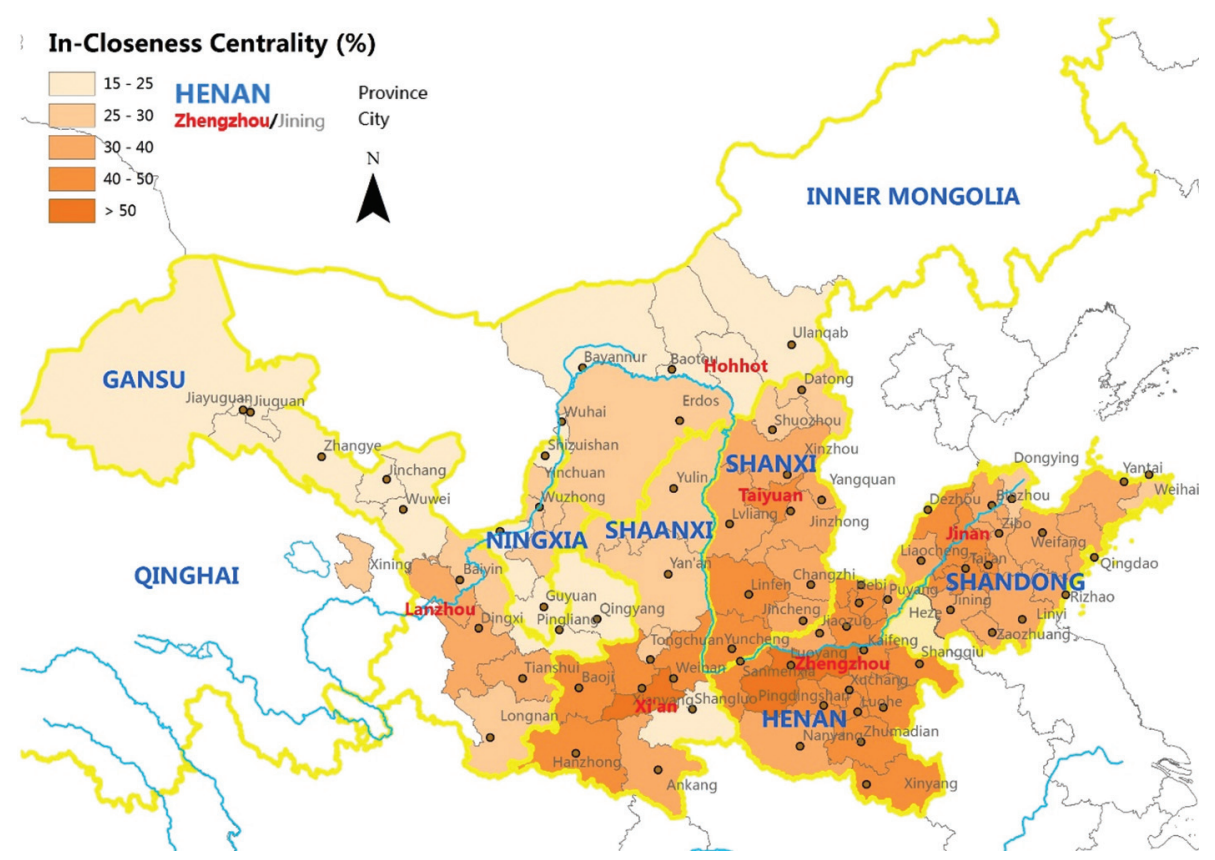

FIGURE 8: Distribution map of in-closeness centrality of cities in the Yellow River basin.

connecting the upper and lower reaches in the east-west direction is significantly weaker than that of Zhengzhou. The central cities present an inverted T-shaped distribution.

The spatial distribution of cities with high network density is shown in Figure 11, showing an inverted T-shaped structure.

4.3. Analysis on Cohesive Subgroups of Cities. The gravity matrix data between cities in the Yellow River basin was put into UCINET6.5 software to analyze the subgroups of the urban network in the Yellow River basin. The result shows that cities in the Yellow River basin can be divided into eight third-class subgroups and four second-class subgroups (Table 5). However, most of the subgroups are links among cities within a province, while the links among subgroups are weak (Figures 12 and 13).

The spatial distribution of cohesive subgroups of city networks in the Yellow River basin is shown in Figure 13.

4.4. Analysis of the Transfer Network of Officials among Cities in the Yellow River Basin. For this study, ArcGIS software was applied to draw the path diagram of officials' transfer 


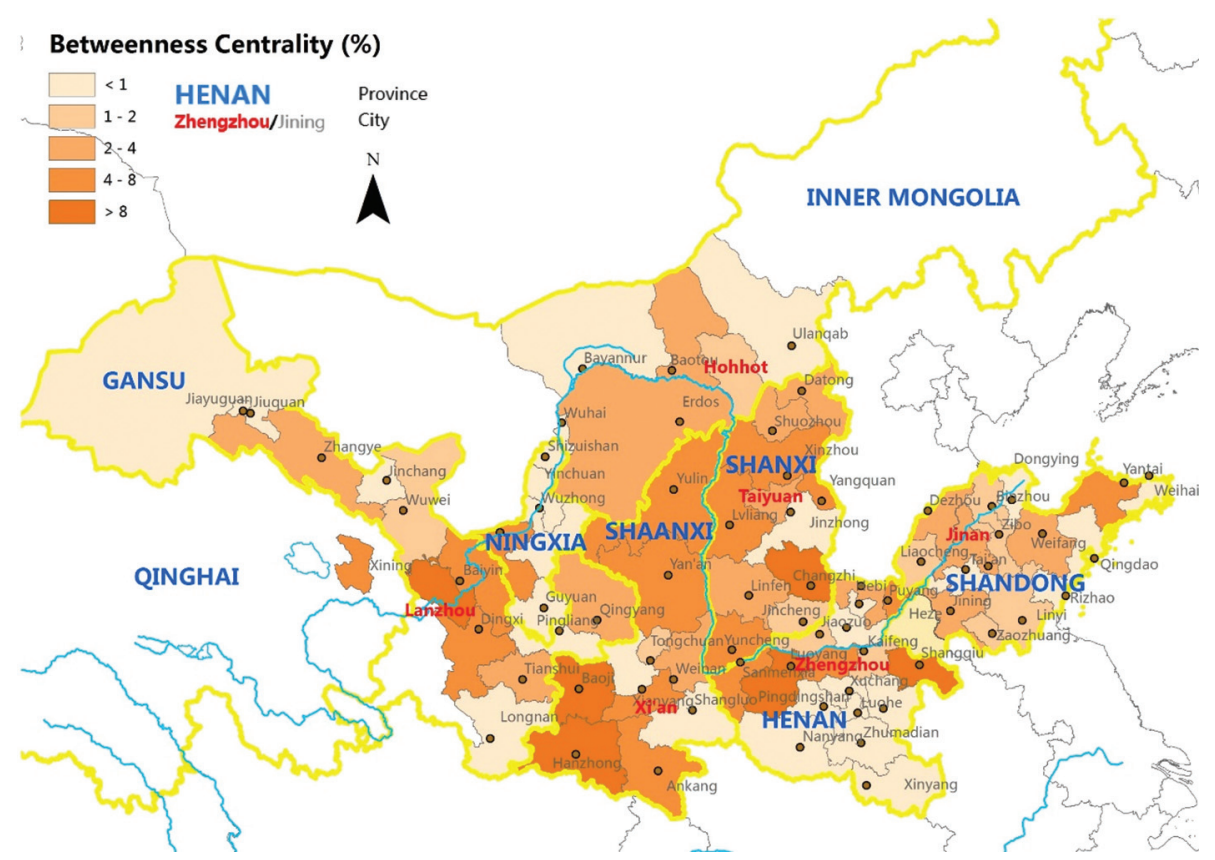

Figure 9: Distribution map of betweenness centrality of cities in the Yellow River basin.

TABLe 4: Average value of city network indexes and city development indexes of the Yellow River basin and its subregions.

\begin{tabular}{|c|c|c|c|c|c|c|c|c|}
\hline Subregion & $\begin{array}{l}\text { Network } \\
\text { density } \\
(\%)\end{array}$ & $\begin{array}{l}\text { Out- degree } \\
\text { centrality } \\
(\%)\end{array}$ & $\begin{array}{l}\text { In- degree } \\
\text { centrality } \\
(\%)\end{array}$ & $\begin{array}{c}\text { Out- } \\
\text { closeness } \\
\text { centrality } \\
(\%)\end{array}$ & $\begin{array}{l}\text { In-closeness } \\
\text { centrality } \\
(\%)\end{array}$ & $\begin{array}{l}\text { Betweenness } \\
\text { centrality }(\%)\end{array}$ & $\begin{array}{l}2019 \\
\text { urbanization } \\
\text { rate }(\%)\end{array}$ & $\begin{array}{c}2019 \text { average } \\
\text { GDP (100 } \\
\text { million yuan } \\
\text { RMB) }\end{array}$ \\
\hline $\begin{array}{l}\text { Overall Yellow } \\
\text { River basin }\end{array}$ & 13.2 & 20.8 & 31.3 & 36.7 & 37.6 & 9.78 & 56.78 & 2262.27 \\
\hline $\begin{array}{l}\text { Zhengzhou urban } \\
\text { agglomeration } \\
\text { Shandong }\end{array}$ & 55.5 & 33.9 & 47.3 & 64.7 & 70.7 & 9.79 & 50.73 & 3904.85 \\
\hline $\begin{array}{l}\text { Peninsula urban } \\
\text { agglomeration }\end{array}$ & 52.5 & 22.2 & 50.6 & 63.0 & 68.1 & 9.08 & 60.99 & 4102.32 \\
\hline $\begin{array}{l}\text { Taiyuan urban } \\
\text { agglomeration }\end{array}$ & 50.0 & 33.0 & 55.0 & 60.8 & 65.0 & 12.63 & 57.79 & 2755.56 \\
\hline $\begin{array}{l}\text { Gansu-Shaanxi } \\
\text { urban } \\
\text { agglomeration }\end{array}$ & 26.5 & 19.8 & 79.1 & 27.9 & 39.1 & 29.28 & 47.35 & 1301.30 \\
\hline $\begin{array}{l}\text { Inner Mongolia- } \\
\text { Ningxia urban } \\
\text { agglomeration }\end{array}$ & 43.6 & 29.0 & 18.0 & 54.9 & 56.2 & 11.75 & 44.10 & 1990.63 \\
\hline
\end{tabular}

among cities in the Yellow River basin, which reflects the political connection and cooperation possibilities among cities. Figures 14 and 15 show the following:

(1) The transfer of officials among cities in the Yellow River basin is mainly within the province and less between provinces. The "network" has not been formed yet, and the regional differences are too great. Therefore, this study does not include this connection in the city network analysis.

(2) "Horizontal transfer" (with the same level of position before and after transfer) is common among cities in the basin, with two-way transfer, but it mainly occurs among noncentral cities. Officials transferred across provinces are usually transferred horizontally. "Promoted transfer" (the official position was promoted after the transfer) is characterized by a oneway transfer from noncentral cities to central cities.

(3) There are far more officials transferred into than transferred out of the regional central cities, and the five cities with the greatest numbers of officials transferred into are Zhengzhou (47), Jinan (40), [[parms resize(1),pos(50,50),size(200,200),bgcol (156)]] central cities provide little support to noncentral cities by transferring excellent officials out, but they have absorbed a great number. 


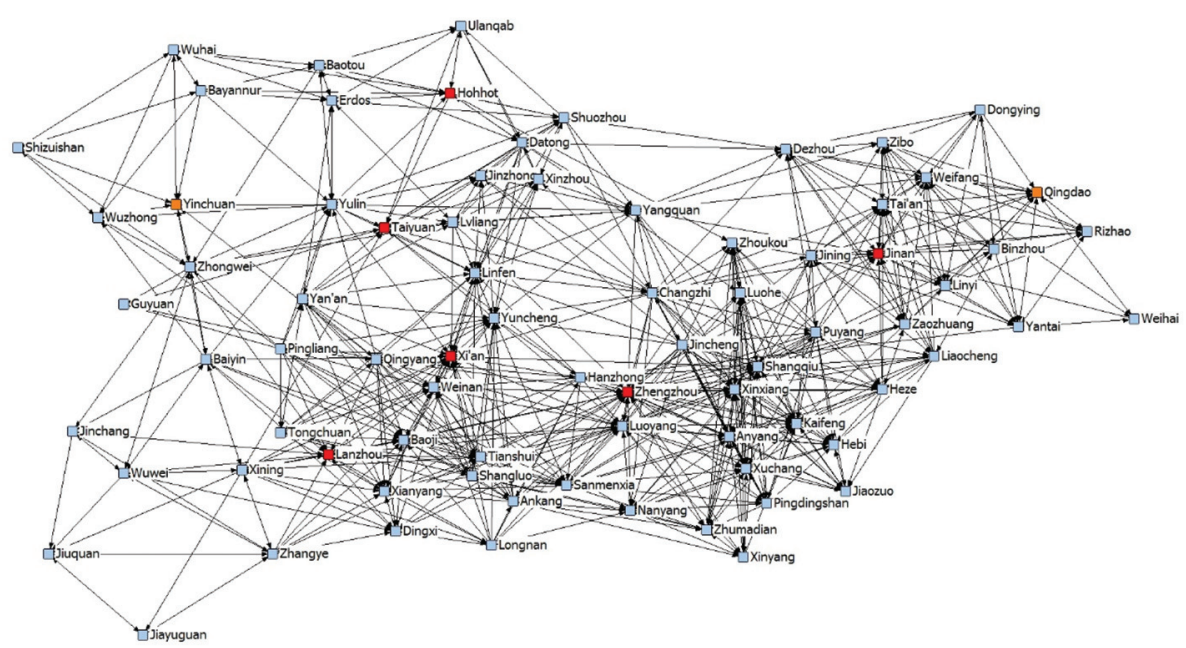

FIgURE 10: Structure of city networks in the Yellow River basin.

TABLE 5: Analysis table of cohesive subgroups of city networks in the Yellow River basin.

\begin{tabular}{|c|c|c|c|c|}
\hline \multirow{2}{*}{ Region } & \multicolumn{2}{|c|}{ The $2^{\text {nd }}$ class subgroup } & \multicolumn{2}{|r|}{ The $3^{\text {rd }}$ class subgroup } \\
\hline & Location & Provinces involved & Area name & Cities involved \\
\hline \multirow{7}{*}{$\begin{array}{l}\text { The Yellow } \\
\text { River basin }\end{array}$} & $\begin{array}{l}\text { North bank of } \\
\text { middle reaches }\end{array}$ & $\begin{array}{l}\text { Inner Mongolia, } \\
\text { Ningxia, and Shanxi }\end{array}$ & $\begin{array}{l}\text { Taiyuan urban } \\
\text { agglomeration } \\
\text { Inner Mongolia, Ningxia } \\
\text { area }\end{array}$ & $\begin{array}{c}\text { Taiyuan, Datong, Jinzhong, Ulanqab, Yizhou, } \\
\text { Shuozhou, Lvliang, Linfen, and Yangquan } \\
\text { Hohhot, Yinchuan, Wuhai, Baotou, Bayannur, } \\
\text { Wuzhong, Ordos, Zhongwei, Yulin, and } \\
\text { Shizuishan }\end{array}$ \\
\hline & \multirow[t]{2}{*}{$\begin{array}{l}\text { Middle and } \\
\text { upper reaches }\end{array}$} & \multirow{2}{*}{$\begin{array}{l}\text { Shaanxi, Gansu, } \\
\text { Qinghai, and part of } \\
\text { Henan, and Shanxi }\end{array}$} & Xi'an urban agglomeration & $\begin{array}{c}\text { Xi'an, Shangluo, Qingyang, Yuncheng, Ankang, } \\
\text { Longnan, Baoji, Tianshui, Hanzhong, Pingliang, } \\
\text { Guyuan, Yan'an, Sanmenxia, Weinan, and } \\
\text { Xianyang }\end{array}$ \\
\hline & & & $\begin{array}{l}\text { Lanzhou-Xining urban } \\
\text { agglomeration }\end{array}$ & $\begin{array}{c}\text { Lanzhou, Xining, Jiayuguan, Jinchang, Jiuquan, } \\
\text { Zhangye, Dingxi, Wuwei, and Baiyin }\end{array}$ \\
\hline & \multirow[b]{2}{*}{ Lower reaches } & \multirow[b]{2}{*}{ Shandong } & $\begin{array}{l}\text { Southern Shandong urban } \\
\text { agglomeration }\end{array}$ & $\begin{array}{c}\text { Dongying, Zaozhuang, Liaocheng, Heze, and } \\
\text { Jining }\end{array}$ \\
\hline & & & $\begin{array}{l}\text { Shandong urban } \\
\text { agglomeration (e.g., } \\
\text { southern Shandong) }\end{array}$ & $\begin{array}{l}\text { Jinan, Qingdao, Zibo, Yantai, Rizhao, Linyi, } \\
\text { Dezhou, Weihai, Tai'an, and Weifang }\end{array}$ \\
\hline & & & $\begin{array}{l}\text { Henan-Shanxi Adjoining } \\
\text { area }\end{array}$ & Changzhi, Jincheng, Jiaozuo, and Puyang \\
\hline & $\begin{array}{l}\text { South bank of } \\
\text { middle reaches }\end{array}$ & $\begin{array}{l}\text { Henan and part of } \\
\text { Shanxi }\end{array}$ & $\begin{array}{l}\text { Zhengzhou urban } \\
\text { agglomeration }\end{array}$ & $\begin{array}{c}\text { Xinxiang, Nanyang, Xinyang, Zhoukou, } \\
\text { Zhumadian, Shangqiu, Xuchang, Luohe, } \\
\text { Zhengzhou, Kaifeng, Luoyang, Pingdingshan, } \\
\text { Anyang, and Hebi }\end{array}$ \\
\hline
\end{tabular}




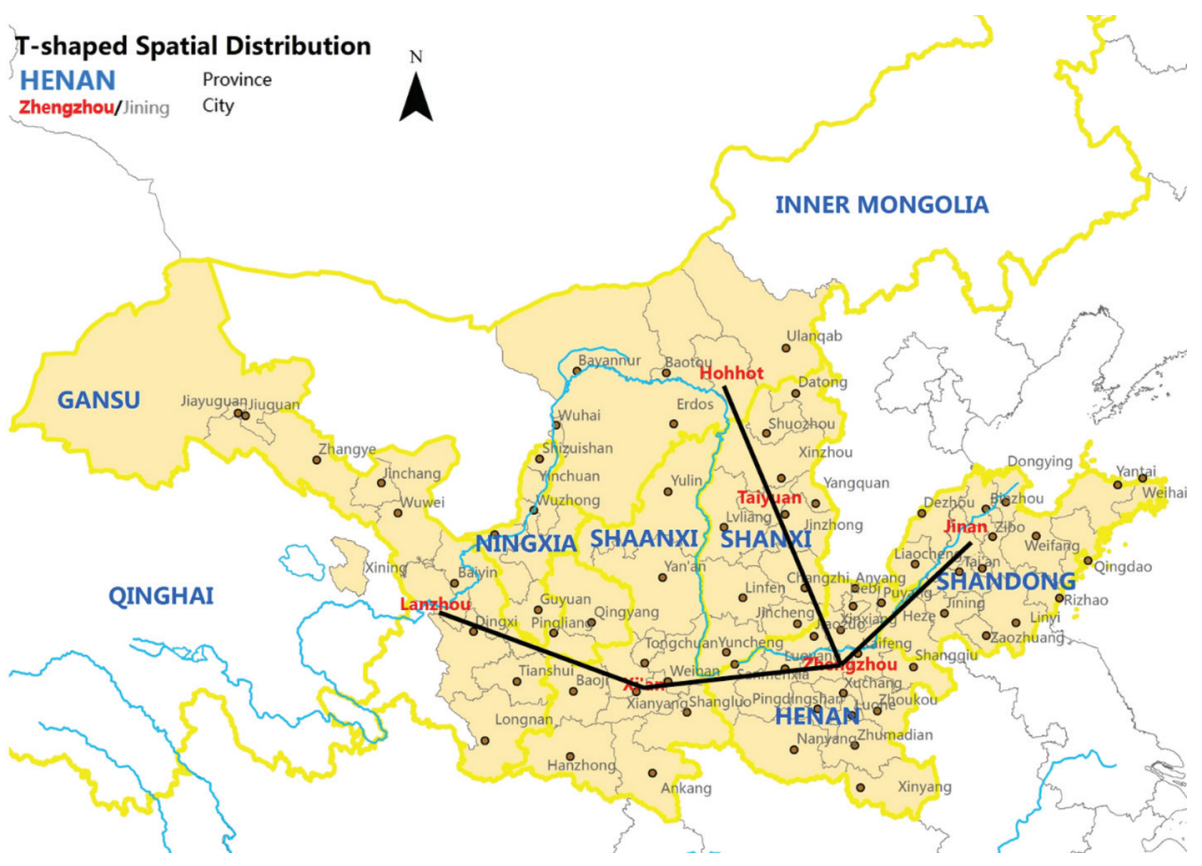

FIGURE 11: Spatial distribution of cities with high network density.

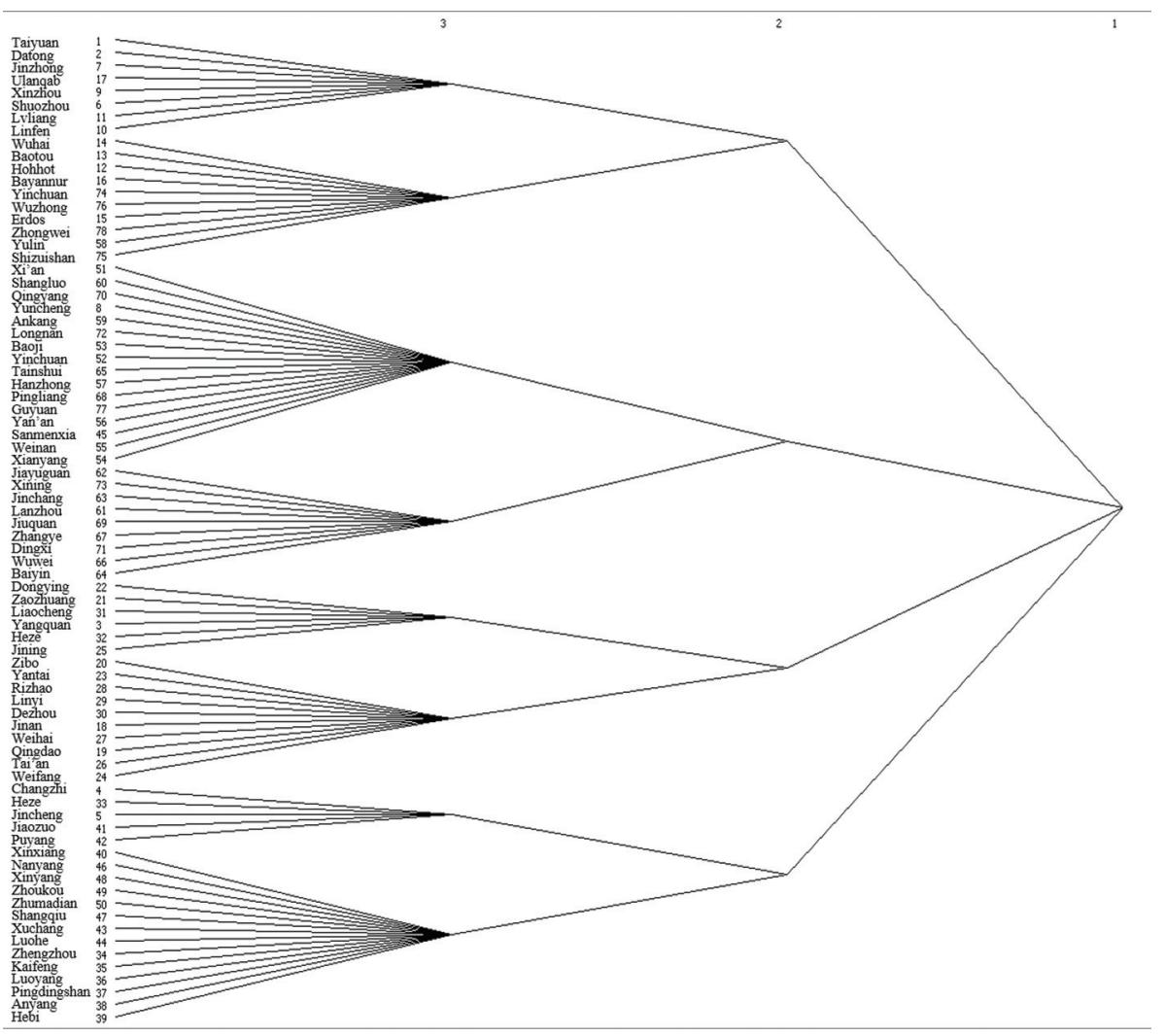

Figure 12: Cohesive subgroups of city networks in the Yellow River basin. 
Cohesive Subgroups of City Networks

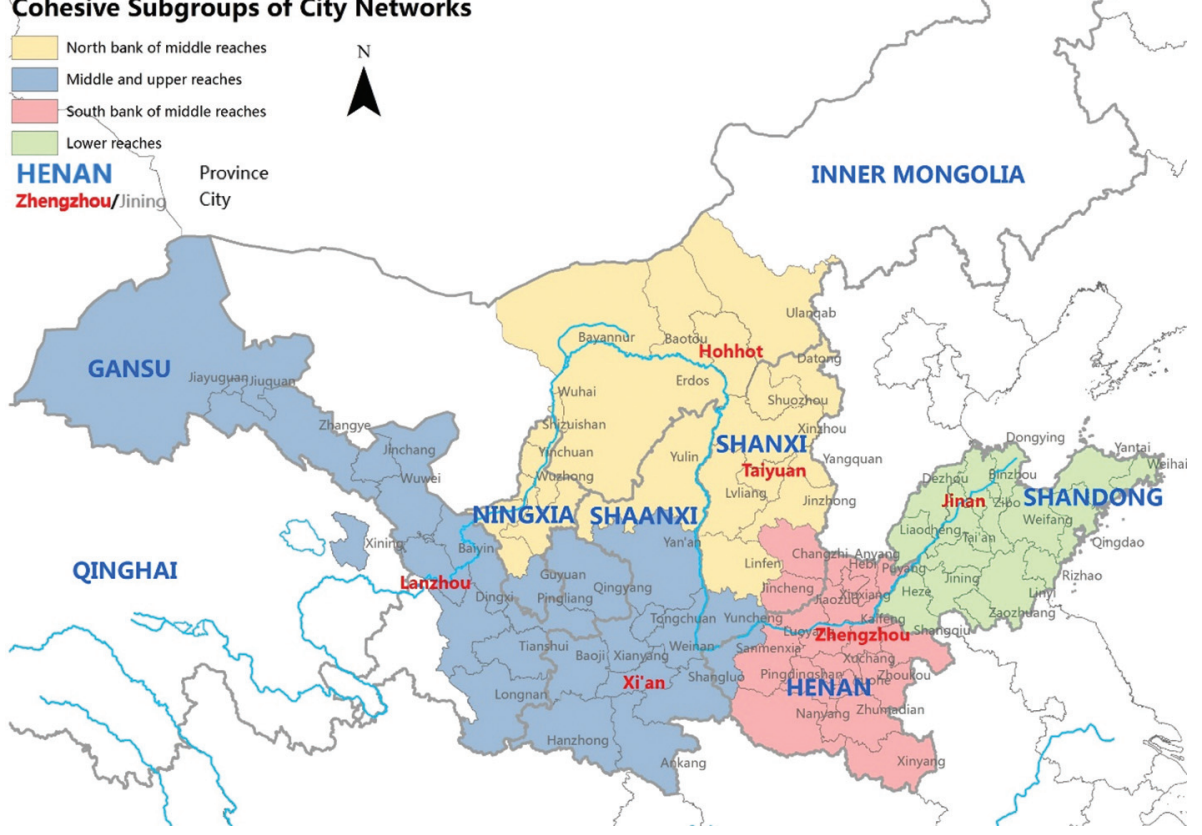

FIgURE 13: Spatial distribution of cohesive subgroups of city networks in the Yellow River basin.

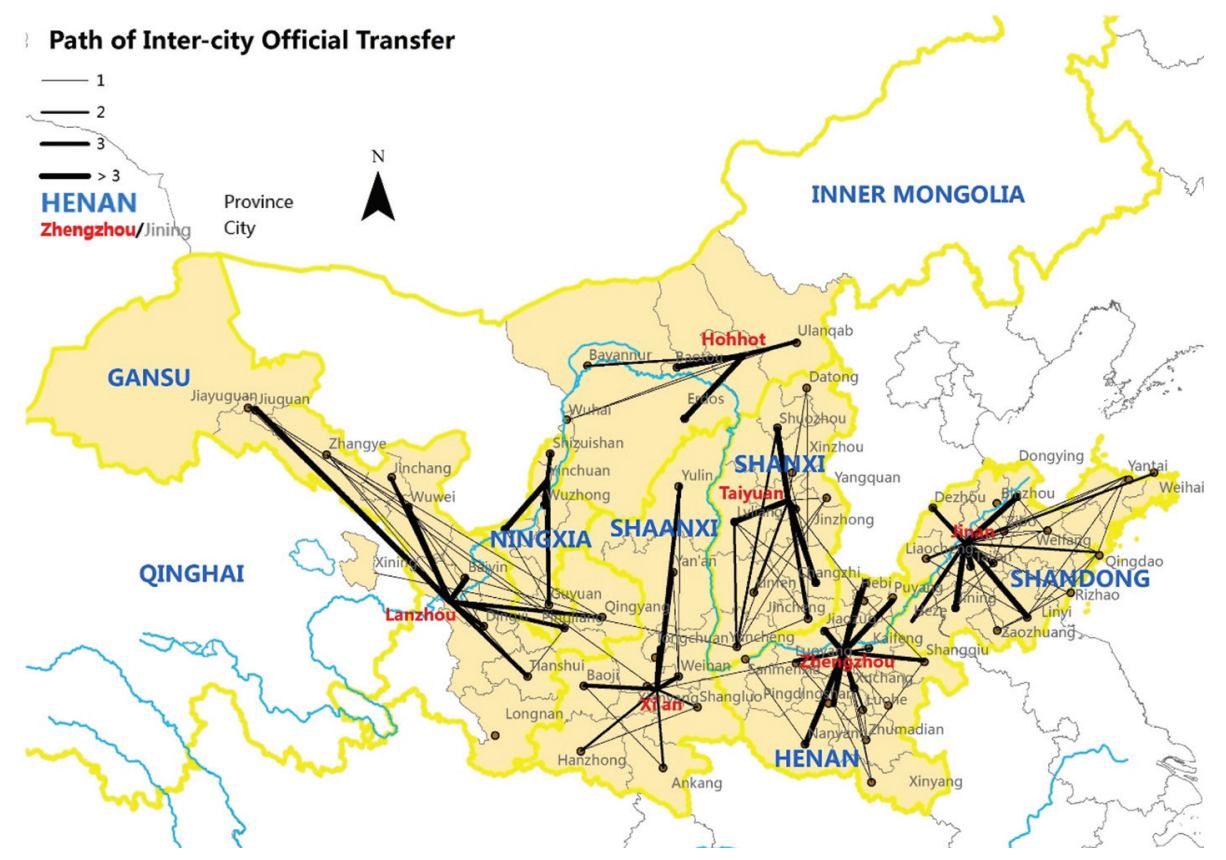

FIgURE 14: Path diagram of intercity official transfer in the Yellow River basin. 


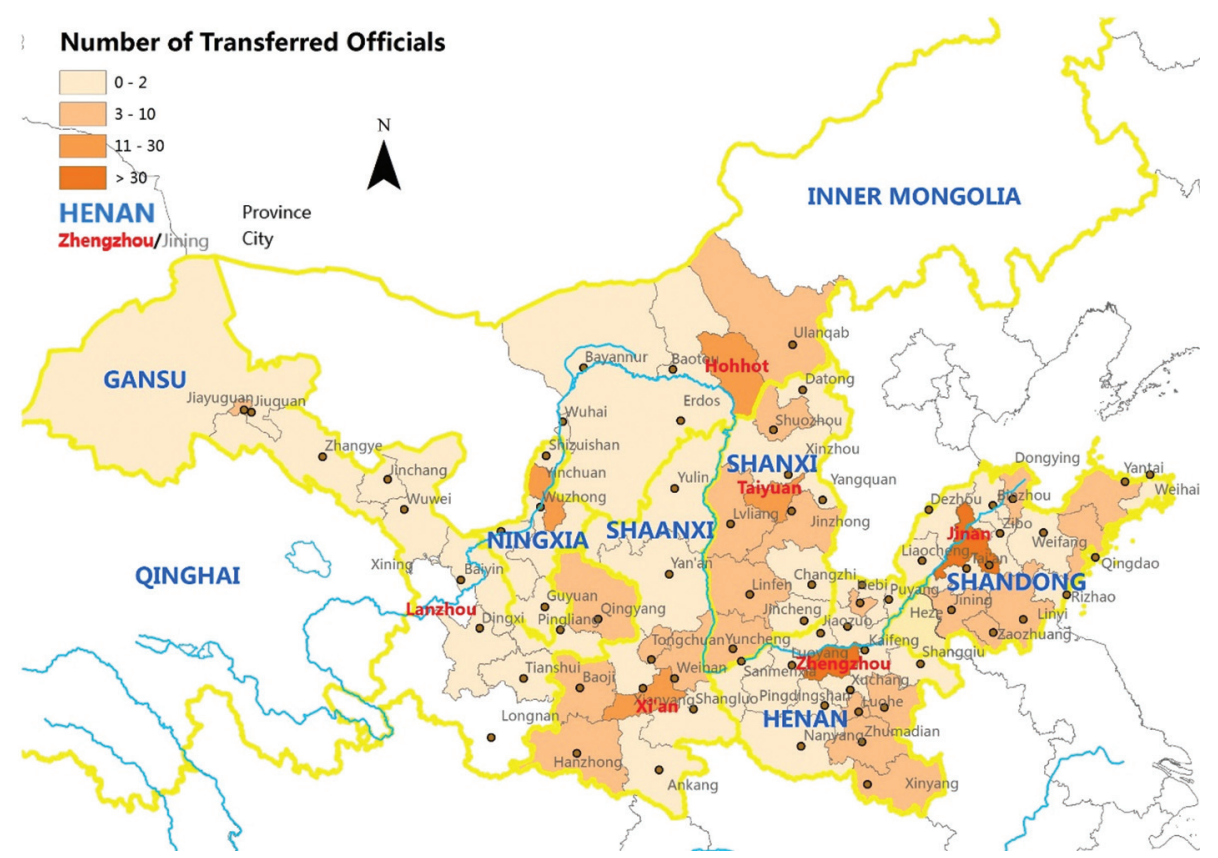

FIGURE 15: Distribution of the numbers of officials transferred into cities in the Yellow River basin.

\section{Conclusion}

In this paper, the entire city network in the Yellow River basin was examined empirically for the first time. The city social network analysis method was improved based on the empirical research on characteristics of the city network in a typical large river basin. It can provide guidance for the planning and policies of urban system construction in the Yellow River basin, as well as reference for other similar regions in the world with lagging development and fragile ecology. The main conclusions are as follows:

(1)The values of intercity connection intensity, outdegree centrality, in-degree centrality, and betweenness centrality of cities in the Yellow River basin are generally low and highly differentiated. The values of intercity connection intensity and city network density are characterized by "south bank$>$ north bank" and "lower reach areas > middle reach areas > upper reach areas," and the development gap between cities on the north and south banks is larger than that between cities on the upper reaches and the lower reaches. The connection intensity of cities in the Yellow River's upper reaches in western China and cities in Inner Mongolia on the north bank is generally lower by more than $80 \%$ than the average value of the overall river basin city network. These cities appear as voids in the city network, are marginalized in the network, and have the problem of isolated development.

(2)The intensity of the two-way connection among cities in the basin is generally similar, but the connection intensity of a few central cities to other cities is significantly higher than that of other cities to themselves. Although the central cities are not strong, the overall "central-edge" city structure in the Yellow River basin is clear. The central cities present an inverted T-shaped spatial distribution as a whole. However, the central cities' weak connecting and leading abilities are a prominent problem in the development of cities in the Yellow River basin.

(3)There is a positive correlation between the city network development level and regional economic development level. Cities in the lower and middle reaches with higher economic development levels have roughly similar two-way intercity connection intensities, while cities in economically underdeveloped areas in the middle and upper reaches have greater numerical differences in interconnection and more unbalanced urban development; the status of the central city and the marginal city is more disparity.

(4) The cohesive subgroups of city networks in the Yellow River basin have a high internal connection intensity, while the connection among cohesive subgroups is weak. Although city networks in different river basin sections exist, the connection among urban agglomerations in the river basin is still weak, and the problem of fragmented development in the river basin is prominent. It is difficult for industries and people to be transferred along the river basin in cascades and to form linkages among the upper, middle, and lower reaches.

Based on the empirical analysis, this paper puts forward some suggestions for development policies and planning of the Yellow River basin:

(1) The Yellow River basin lacks central cities with strong economic and leading capabilities, so it is 
difficult to copy the strategy of taking developed cities in Shanghai, Jiangsu, and Zhejiang as economic cores and leading inland development as in the Yangtze River basin of China. The strategy of "beaded chain" can be adopted; i.e., the four secondary cohesive subgroups of city networks (Figures 12 and 13) in the Yellow River basin can be taken as the zoning scheme of the recent basin planning, giving priority to strengthening the internal connections within the secondary subgroups, such as vigorously developing intercity railways. Connection of various infrastructures among adjacent subgroups should be gradually strengthened, and the interconnected development among the upper, middle, and lower reaches should be promoted.

(2) In the near future, the layout of central city construction can be based on the current inverted $\mathrm{T}$-shaped structure, and the economy and industrial policies, resources, and infrastructure construction in the basin should be given key support. First, an east-west core city chain of Lanzhou-Xi'an-Zhengzhou-Jinan connecting the upper and lower reaches should be built. Then, taking Zhengzhou as the intersection of the T-shape, the core cities in the Yellow River basin that connect the upper and lower reaches could be cultivated, and Xi'an City, Lanzhou City, and Jinan City developed as subcenters. Changzhi City and Taiyuan City of Shanxi Province in the central region could be used as the main connecting channels between the north and south banks of the Yellow River basin, to gradually strengthen the construction of traffic channels between the north and south banks of the Yellow River in other regions. This would resolve the imbalanced development between the north and south banks.

(3) Regional node cities should be cultivated in regions with relatively few connection nodes in the middle and upper reaches of the Yellow River. Yinchuan City of Ningxia Autonomous Region, Yulin City and Yan'an City of Shaanxi Province, Dingxi City and Zhangye of Gansu Province, and Xining City of Qinghai Province could be priority choices.

(4) Because the ecological environment in the Yellow River basin is fragile and the economic power of the cities is weak, resources for the construction of intercity connection facilities must be jointly provided by relevant cities to improve the efficiency of resource utilization and to avoid duplicated construction. Therefore, it is important to learn from the systems of the Tennessee Valley Authority (TVA) in the USA, the International Commission for the Protection of the Rhine (ICPR) in Europe, and the Yangtze River Economic Belt Committee in China, improve the functions and jurisdiction of the Yellow River Committee, and strengthen the pace of coordination in policies, funds, and infrastructure construction in the region.

(5) The current situation whereby most of the outstanding city officials in the Yellow River basin transfer into the central cities is unfavorable for the development of backward areas. The outstanding officials from lower reach provinces should be transferred to upper reach provinces and from central cities to other cities to enhance connection and cooperation among cities and to support the development of underdeveloped cities.

Problems for the future on this topic include the following:

(1) Due to the lack of data on the point-to-point traffic volume of various modes of transportation through roads and railways among cities in the basin, this study has not considered the traffic volume of various modes of transportation in calculating time distance, in order to simplify the analysis for the time being. This is also a common problem in all studies at present $[20-22,24,28]$. In the future, the method for this study could be further improved after the establishment of big data resources for intercity transportation in the Yellow River basin.

(2) The idea of gravity modelling in this paper shows that the connection intensity between two cities is directly proportional to the economy and population size of the two cities and inversely proportional to commuting time, while the ecological connection has not been considered. With the strengthening of ecological protection of the Yellow River in China, we can introduce an ecological aspect into the study after more detailed data on ecological functional areas in the basin are established.

(3) In subgroups of city networks in the Yellow River basin, the impact of the cross-city transfer of city officials on the formation of city network may be further studied in the future to reveal the effects of official ties between cities.

\section{Data Availability}

The economic, social, and demographic data supporting this study are from the 2019 China City Statistical Yearbook and the statistical yearbooks of the provinces or autonomous regions in China. The processed data are available in the Supplementary Files (1). The original data are available from the corresponding author upon request. Intercity highway and railway commuting time data used to support the findings of this study are available from Google Maps and the China Railway Customer Service Center. The original data are available in the Supplementary Files (2). The transfer experience of mayors, deputy mayors, and secretaries of municipal CPC party committees' data supporting this study comes from the official websites of China's national and provincial governments, People's Daily Online, 
Xinhua Net, and local chronicles of cities. The data are the phased achievement of the National Natural Science Foundation of China. The processed data are available in the Supplementary Files (3). Requests for original data, six months after publication of this article, will be considered by the corresponding author. The GIS data supporting spatial analysis and mapping in this study are from the National Geomatics Center of China http://www.ngcc.cn/ngcc/html/ 1/391/392/16114.html. The processed data are available from the corresponding author upon request.

\section{Conflicts of Interest}

The authors declare that there are no conflicts of interest regarding the publication of this paper.

\section{Acknowledgments}

This study was supported by the National Natural Science Foundation of China (Grant no. 71974220). The authors also gratefully acknowledge many useful insights by Professor Yan Song of the University of North Carolina at Chapel Hill.

\section{Supplementary Materials}

Supplemental file (1): these include the economic, social, and demographic data. Supplemental file (2): these contain matrix of the shortest time distance between cities. Supplemental file (3): these are the transfer experience of city officials in the Yellow River basin. Supplemental file (4): these carry gravity model results. Supplemental file (5): these are the results of cities' degree centrality, closeness centrality, and betweenness centrality in the city networks of the Yellow River basin. (Supplementary Materials)

\section{References}

[1] S. Hennemann, B. Derudder, and P. J. Taylor, "Cutting the Gordian knot of visualizing dense spatial networks: the case of the world city network, 2013," Environment \& Planning A, vol. 47, no. 6, pp. 1332-1340, 2015.

[2] B. Derudder and P. J. Taylor, "Change in the world city network, 2000-2012,” The Professional Geographer, vol. 68, no. 4 , pp. 624-637, 2016.

[3] J. V. Beaverstock, M. A. Doel, P. J. Hubbard, and P. J. Taylor, "Attending to the world: competition, cooperation and connectivity in the world city network," Global Networks, vol. 2, no. 2, pp. 111-132, 2002.

[4] X. Ma and G. Li, "Study on world city network theory within global space of flow," Economic Geography, vol. 31, no. 10, pp. 1630-1637, 2011.

[5] J. Jiao, J. Wang, F. Jin, and H. Wang, "Impact of high-speed rail on inter-city network based on the passenger train network in China, 2003-2013," Acta Geographica Sinica, vol. 71, no. 2, pp. 256-280, 2016.

[6] M. Li and L. Y. Wang, "Discussing how to extract city characteristic with the examples of ancient capital cities in the Yellow River Basin," China Ancient City, no. 5, pp. 25-30, 2017.

[7] H. Liu, L. Wang, Q. Li et al., "Spatial and temporal patterns of city connection networks in the Yellow River Basin based on
Tencent's big data of population migration," Economic Geography, vol. 40, no. 4, pp. 28-37, 2020.

[8] The Political Bureau of the CPC Central Committee, "Outline of ecological protection and high quality development plan of the Yellow River Basin," China Water Conservancy, vol. 70, no. 6, p. 6, 2020.

[9] J. Xi, "Speech at the symposium on ecological protection and high quality development in the Yellow River River Basin," China Water Resources, no. 20, pp. 1-3, 2019.

[10] S. Ardekani and R. Herman, "Urban network-wide traffic variables and their relations," Transportation Science, vol. 21, no. 1, pp. 1-16, 1987.

[11] D. A. Smith and M. F. Timberlake, "World city networks and hierarchies, 1977-1997: an empirical analysis of global air travel links," American Behavioral Scientist, vol. 44, no. 10, pp. 1656-1678, 2001.

[12] P. J. Taylor, G. Catalano, and D. R. F. Walker, "Exploratory analysis of the world city network," Urban Studies, vol. 39, no. 413, pp. 266-279, 2002.

[13] J. H. Choi, G. A. Barnett, and B.-S. Chon, "Comparing world city networks: a network analysis of internet backbone and air transport intercity linkages," Global Networks, vol. 6, no. 1, pp. 81-99, 2010.

[14] C. A. Jarmon and J. M. Vanderleeuwm, "City leaders and economic development networks: the all-channel star network," Journal of Political Science, vol. 19, pp. 1-32, 2011.

[15] Z. Neal, "Validity in world city network measurements," Tijdschrift Voor Economische en Sociale Geografie, vol. 105, no. 4, pp. 427-443, 2014.

[16] X. Jin, G. Hu, H. Ding, S. Ye, Y. Lu, and J. Lin, "Evolution of spatial structure patterns of city networks in the Yangtze River economic belt from the perspective of corporate pledge linkage," Growth and Change, vol. 51, no. 8, pp. 833-851, 2020.

[17] C. Varol, O. Y. Ercoskun, and N. Gurer, "Local participatory mechanisms and collective actions for sustainable urban development in Turkey," Habitat International, vol. 35, no. 1, pp. 9-16, 2011.

[18] E. C. Jennifer and A. R. Angel, "Mississippi gulf coast advances sustainability plan," Biocycle, vol. 53, no. 1, pp. 52-55, 2012.

[19] D. Wang and R. Zhuang, "The preliminary probe into the quantitative analysis of regional economic links," Scientia Geographica Sinca, vol. 16, no. 1, pp. 51-57, 1996.

[20] G. Li, L. Wang, and K. Yang, "The measurement and analysis of economic relationship between Shenzhen and Zhujiang delta," Economic Geography, vol. 21, no. 1, pp. 33-37, 2001.

[21] H. Wu, Y. Shen, and Q. Hu, "Spatial correlation characteristics of economic growth in Beijing-Tianjin-Hebei Region and its explanation: based on spatial autocorrelation and network analysis," Jiangxi Social Science, vol. 36, no. 3, pp. 75-80, 2016.

[22] S. Wang, Y. Song, Y. Zhang, and J. Li, "Spatial organization and driving mechanism of connected network of urban agglomeration in the middle reaches of the Yangtze River," Economic Geography, vol. 40, no. 6, pp. 87-97, 2020.

[23] C. Li, "City network structure of Shandong province based on information flow," Journal of Arid Land Resources and Environment, vol. 29, no. 12, pp. 51-56, 2015.

[24] C. Wang and M. Wang, "Evolution of associated network characteristics between cities in Shandong Province: comparing central place and flow space theories," Geographical Research, vol. 36, no. 11, pp. 2197-2212, 2017. 
[25] Y. Cheng and L. Wang, "Reinterpretation of the theory of central place in a context of space of flow: a study on provincial city network in Shandong Province," Economic Geography, vol. 37, no. 12, pp. 25-33, 2017.

[26] S. Zhao, H.-Y. Zhou, and L.-J. Zhu, "Appling the Voronoi map to the research on the city network of Henan," Journal of Institute of Surveying and Mapping, vol. 20, no. 3, pp. 206-209, 2003.

[27] C. Miao and H. Wang, "On the direction and intensity of urban economic contacts in Henan Province," Geographical Research, vol. 25, no. 2, pp. 222-232, 2006.

[28] D. Meng and Y. Lu, "Impact of high-speed railway on accessibility and economic linkage of cities along the railway in Henan Province, China," Scientia Geographica Sinica, vol. 31, no. 5, pp. 537-543, 2011.

[29] Q. Song and J. Liu, "Research on structure of urban network among Zhongyuan urban agglomeration based on the industrial perspective," Henan Science, vol. 34, no. 3, pp. 424430, 2016.

[30] T. Geng and J. Li, "The research of Shaanxi Province city network connection based on Baidu index," Henan Science, vol. 34, no. 7, pp. 1166-1172, 2016.

[31] H. He and B. Lyu, "The measurement on economic connection in Changzhutan urban agglomeration," Economic Geography, vol. 34, no. 7, pp. 67-74, 2014.

[32] P. Chong, S. Chen, and B. Wang, “Analyzing city network's structural resilience under disruption scenarios: a case study of passenger transport network in the middle reaches of Yangtze River," Economic Geography, vol. 39, no. 8, pp. 68-76, 2019.

[33] F. Peng, "Economic spatial connection and spatial structure of Guangdong-Hong Kong- Macao Greater Bay and the surrounding area cities: an empirical analysis based on improved gravity model and social network analysis," Economic Geography, vol. 37, no. 12, pp. 57-64, 2017.

[34] H. Meng, X. Huang, and J. Yang, "Network structure and development concept in Huaihai economic zone," Economic Geography, vol. 39, no. 12, pp. 1-10, 2019.

[35] J. Guo, S. Wang, B. Li, and J. Guo, "The spatial effect of Harbin-Dalian high-speed rail to the northeast city tourism economic link," Scientia Geographica Sinica, vol. 36, no. 4, pp. 521-529, 2016.

[36] J. Tinbergen, Shaping the World Economy: Suggestions for an International Economic Policy, Twentieth Century Fund, NewYork, NY, USA, 1962.

[37] K. Zhao and Y. Wu, "Study on evolution characteristics and synergy between high-speed railway network and economic network in China," East China Economic Management, vol. 34, no. 2, pp. 77-85, 2020.

[38] J. Wang, J. Jiao, and F. Jin, "Spatial effects of high-speed rails on interurban economic linkages in China," Acta Geographica Sinica, vol. 69, no. 12, pp. 1833-1846, 2014.

[39] A. W. Wolfe, "Social network analysis: methods and applications," Contemporary Sociology, vol. 91, no. 435, pp. 219-220, 1995.

[40] S. Wang, Y. Song, H. Wen et al., "Network structure analysis of urban agglomeration in the Yangtze River economic belt under the perspective of bidirectional economic connection: based on time distance and social network analysis method," Economic Geography, vol. 39, no. 2, pp. 73-81, 2019.

[41] D. Nepelski and G. De Prato, "Corporate control, location and complexity of ICT R\&D: a network analysis at the city level," Urban Studies, vol. 52, no. 4, pp. 721-737, 2015.
[42] X. Li, "Research on the Yangtze River delta urban agglomeration network structure based on social network analysis," Urban Studies, vol. 18, no. 12, pp. 80-85, 2011. 